\title{
Particularities of the changes in young swimmers' body adaptation to the stimuli of physical and mental stress in sports training process
}

\author{
Liliana Mihailescu $^{1}$, Nicoleta Dubiț ${ }^{2}$, Liviu Emanuel Mihailescu $^{3}$, Vladimir Potop $^{\text {Corresp. } 1,3,4}$ \\ 1 Doctoral School of Sports Science and Physical Education, University of Pitesti, Pitesti, Romania \\ 2 Pitesti High School with Sports Program, Pitesti, Romania \\ 3 Departament of Physical Education and Sport, University of Pitesti, Pitesti, Romania \\ ${ }^{4}$ State University of Physical Education and Sport, Chisinau, Republic of Moldova \\ Corresponding Author: Vladimir Potop \\ Email address: vladimir_potop@yahoo.com
}

Background A factor favoring the swimming performance increase is the adaptation and readaptation of body energetic and functional systems to the physical and mental stress stimuli in training and competitions. The efficiency of monitoring the young swimmers' training is based on a precise determination of the changes in the specific adaptations. The evaluation and control of the biochemical, mental and motor changes ensure the knowledge of the particularities of body adaptation in different training stages. Methods Six young swimmers aged 12 - 16 years specialized in $100 \mathrm{~m}$ event participated in this study, conducted in 4 stages (E1- general, E2 - specific, E3 - pre-competitive and E4 competitive). The distress occurrence during adaptation to training and competition stimuli was studied in 3 levels: mental (Cohen \& Williamson Test (CWT), Cohen Perceived Stress Test (CPST), Competition Anxiety Test (SCAT), Crăciun Test (CT)), motor (workouts monitoring, planning of means on training areas, anaerobic threshold assessment and average training speed calculation) and biochemical (blood lactate (La) and blood glucose (Glu) before and after effort - 5 and 15 minutes; level of metabolic biochemical parameters, lymphocytes and blood glucose, and also hormonal parameters norepinephrine, prolactin and cortisol- before and after competition effort). Results Quantity results of the mental, motor and biochemical tests were analyzed in groups; the quality results for each subject in dynamics were analyzed by comparison and correlation. Psychological tests showed increases in athletes' mental behavior by $34 \%$ at CWT ( $p<$ 0.05 ), by $37.5 \%$ at CPST ( $p<0.05$ ), average stress level at SCAT and $70 \%$ stress in selfconfidence at CT $(p<0.01)$. Biochemical tests revealed an ascending dynamics of La accumulated after specific effort, with peaks in E2 period $(p<0.05)$ and decreases in E3 compared to E2 ( $p<0.05)$, revealing the adaptation to specific effort and the increase in 
anaerobic capacity. The Glu values decrease in pre-effort and increase in minute 5 and 15 post-effort ( $p<0.05)$ in E2 and decrease in pre- and post- effort in E3 ( $p<0.05)$, showing the effort impact on body and ability to recover after effort. Athletes' individual metabolic results were $50 \%$ above maximum values, mainly post-effort ( $42 \%)$; hormonal results were $17 \%$ over maximum values, mainly post-effort (14\%). Spearman's correlative analysis of the induced-stress stimuli in workouts revealed $6.06 \%$ significant correlations at $p<0.05$ and $9.1 \%$ strong connections in competitions: $4.67 \%$ significant correlations at $p<0.05$ and $6.4 \%$ strong connections. Conclusion The research demonstrated that the mental and biochemical tests results correlation with the specific motor tests facilitated the correct individualization of effort orientation in training and recovery and contributed to the knowledge of the particularities of young swimmers' body adaptation to training and competition effort. 


\section{Particularities of the changes in young swimmers'}

3 body adaptation to the stimuli of physical and mental

4 stress in sports training process

5

6

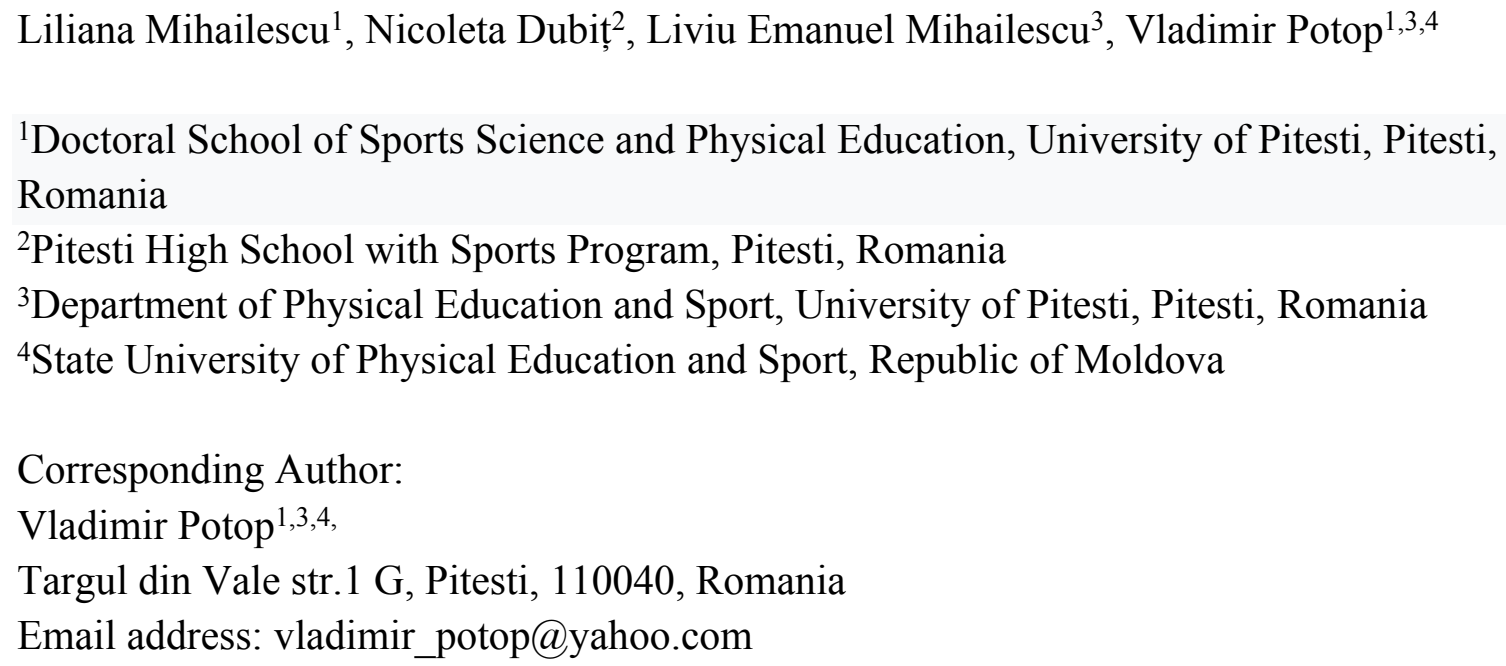

\section{Abstract}

\section{Background}

One of the factors favoring the increase of swimming performance is the adaptation and readaptation of the energetic and functional systems to the body to the stimuli of physical and mental stress in training and competitions. The efficiency of the use of monitoring the training in young swimmers requires a precise determination of the changes occurred in the specific adaptations. The evaluation and control of the biochemical, mental and motor changes ensure the knowledge of the particularities of body adaptation of the young swimmers in different stages of the training.

\section{Methods}

Six young swimmers of $12-16$ years old specialized in $100 \mathrm{~m}$ in different styles participated in this study, conducted in 4 stages (E1- general, E2 - specific, E3 - pre-competitive and E4 competitive). The investigation of distress occurrence during adaptation to training and competition stimuli was made in 3 levels: mental (Cohen \& Williamson Test (CWT), Cohen Perceived Stress Test (CPST), Competition Anxiety Test (SCAT), Crăciun Test (CT)), motor (monitoring the workouts, planning the means on training areas, assessing the anaerobic threshold and calculating the average training speed) and biochemical (blood lactate (La) and blood glucose (Glu) before and after effort - minutes 5 and 15; level of metabolic biochemical parameters, 
38 lymphocytes and blood glucose, and also hormonal parameters -norepinephrine, prolactin and

39

40

41

42

43

44

45

46

47

48

49

50

51

52

53

54

55

56

57

58

59

60

61

62

63

64

65

66

67

68

69

70

71

72

73

74

75

76

77

cortisol- before and after competition effort - in specialized $100 \mathrm{~m}$ event).

\section{Results}

Quantity results of the mental, motor and biochemical tests were analyzed in groups, while the quality results for each subject in dynamics were analyzed by comparison and correlation, for monitoring objectively the individual response to training and competition stimuli. The psychological tests showed increases and changes in athletes' mental behavior by $34 \%$ at CWT $(p<0.05)$, by $37.5 \%$ at CPST $(p<0.05)$, an average level of stress at SCAT and $70 \%$ stress in cognitive and self-confidence at CT $(p<0.01)$. The biochemical tests revealed an ascending dynamic of La accumulated after specific effort, with peaks in E2 period $(p<0.05)$ and decreases in E3 compared to E2 $(p<0.05)$, which reflected an adaptation to the specific effort and an increase in anaerobic capacity. The highlighted values of Glu decrease in pre-effort and increase in minute 5 and 15 post-effort $(p<0.05)$ in E2; as for E3, the values had decreases in pre-effort and post-effort - minute 5 and $15(p<0.05)$, which highlighted the effort impact on body and ability to recover after effort. Athletes' individual metabolic results were $50 \%$ above maximum values, mainly post-effort (42\%); the hormonal results were $17 \%$ above the maximum values, mainly post-effort (14\%). Spearman's correlative analysis of the induced-stress stimuli during workouts revealed $6.06 \%$ significant correlations at $p<0.05$ and $9.1 \%$ strong connections in competitions there are $4.67 \%$ significant correlations at $p<0.05$ and $6.4 \%$ strong connections.

\section{Conclusion}

The research demonstrated that the correlation of the mental and biochemical tests results with the specific motor tests facilitated the correct individualization of effort orientation in training and recovery. It also contributed to the knowledge of the particularities of young swimmers' body adaptation to training and competition effort.

\section{Introduction}

The adaptation and permanent readaptation of human body systems to the training stimuli is the functional spring of progress in sports performance, provided that they are optimal individually. (Mellalieu et al., 2009; Mihăilescu, 2018).

The specialists of this field - Bompa (2002), Dragnea \& Teodorescu-Mate (2002), Platonov (2015), Şalgău (2005) - state that it is a biological necessity to reach the over compensation after performing a number of training sessions, because the processes of body adaptation are superior to the ones in the previous training. During the preparatory period, the chronic fatigue syndrome is caused by successive overloaded microcycles, with insufficient recovery periods that influence three major areas: the neuromuscular system, the metabolic system and the neuro-endocrine system. The practice of the modern sports training highlights that the optimization of the sports results achieved by the athletes adapted to intense efforts is determined by the training method based on the relationship between effort-fatigue-stress; this method is the basis of the training. Nowadays, when the sports results in swimming events exceed the capacity of the body, it is very usual to monitor the functional state of the swimmers during a training macrocycle, to analyze the physiological, kinematical and performance changes, to identify the contributions of

Peer) reviewing PDF | (2021:01:57290:3:0:NEW 23 May 2021) 
78 the technique and energetic, bioenergetic and anthropometric profiles (Bădescu and Galeru. 79 2009; Dias et al., 2012; Tucher et al., 2019; Zacca et al., 2018, 2019). The training principles: 80 specificity, overload, progressiveness, tempo, rhythm and adaptability used in the training of 81 senior swimmers shall be also respected in the training of cadet (12-14 years old) and junior (148216 years old) swimmers. Also, the swimmers aged 12 to 16 years will train in the effort areas 83 taken over from Maglischo, (1993). Depending on the sports branch and the sports event, two 84 categories of training sessions are needed: endurance training to improve the aerobic metabolism 85 86

and sprint training to improve the anaerobic metabolism and strength (Maglischo, 2003; Şalgău, 2005).

The relationship between recovery and fatigue and its impact on performance has attracted the interest of sport science for many years. An adequate balance between stress (training and competition load, other life demands) and recovery is essential for athletes to achieve continuous high-level performance (Kellmann, and Beckmann, 2018; Kellmann et al., 2018).

In swimming, the workouts are dominated by the aerobic ergogenesis; the water in the swimming pool imposes a series of adaptive processes (e.g. Drăgan, 2002). The specialists focused also on the following matters: the acute biochemical and physiological responses to swimming training series performed at intensities based on the 400-m freestyle speed (e.g. Franken et al., 2018); the determination of the effect of 12 weeks of training on the critical velocity and maximal lactate steady state of elite swimmers (e.g. Machado et al., 2011); the classification, identification and follow-up of young swimmers' performance; the biomechanical determinants during two competitive seasons; the analysis of the individual variations in each swimmer (e.g. Morais et al., 2019).

From a psychological point of view, stress can be often confused with emotions that become a source of stress in the interpersonal relationships (e.g. Godoy-Izquierdo et al., 2011). In general, on the one hand, the stress is the negative side of distress, which causes decreased performances, decreased efficiency and the onset of disease (Grosu et al., 2015; Ware \& Matthay, 2000); on the other hand, a positive side is described - the eustress which manifests itselfasa pleasant, dynamic, stimulating and exciting experience; people feel able to cope successfully with the demands they face and they put themselves in challenging situations that they know how to control. In this case, the stress works for us to improve our achievements (e.g. Šarotar-Žižek et al., 2013).

The prolactin increases in acute and rapid stress; at another occurrence of stress, the prolactin decreases or is even refractory. In chronic stress, prolactin is low and cortisone is increased. Stress hormones include: catecholamines, glucocorticoids, growth hormones, prolactin, vasopressin and endogenous opioids (e.g. Drăgan, 2002). The measurement of cortisol in saliva provides a reliable tool for investigations of hypothalamus-pituitary gland-adrenal gland axis activity and may be suitable for the psychobiological studies (Kirschbaum and Hellhammer, 1989). In competitive activity, the effects of victory and defeat on the response to testosterone and cortisol reveal percentage changes in hormone levels almost identical in both genders (e.g. Jiménez et al., 2012).

Peer) reviewing PDF | (2021:01:57290:3:0:NEW 23 May 2021) 
118 The interdisciplinary approach in the fields of sports training theory (e.g. Platonov, 2015), 119 swimming (Smith et al. 2002; Salgau et al., 2008; Mrakic-Sposta et al., 2015), medicine 120 (Papadopoulos et al. 2014; Whdan, 2014) and psychology has made valuable contributions to 121 the identification of the parameters that determine the occurrence of stress and has revealed its 122 relationship with performance capacity both in training and competition (Anshel, 2001; 123 Matthews et al., 2005; Souglis and Travlos, 2015; Vovkanych and Penchuk, 2015). Thus, 124 Niemana and Wentz (2019) describe the influences that physical activity has on the immunity 125 system of the body but also their metabolic aspects; Carrasco, et al. (2007) and Stroud, et al. 126 (2009) analyzed the neuroendocrine and cardiovascular responses tostress induced in the course 127 of swimming training sessions and competitions. The authors Kanaleyet al. (2001), Crewther et

128

129

130

131

132

133

134

135

136

137

138

139

140

141

142

143

144

145

146

147

148

149

150

151

152

153

154

155

156 al. (2013) and Soria et al. (2015) determined and analyzed the variation of stress hormones during the elementary physical exercises but also in performance sports; they consider that physical exercises of high intensity are a powerful stimulant for cortisol secretion.

We emphasize that one of the factors that can influence the results could be the control over the coaching styles during the training as a response factor to stress in young swimmers. An autocratic coaching style modulates the release of cortisol in both genders, affecting the motivational climate and the training experience of young elite swimmers. The direct and indirect relations between the coaching styles and the athletes' intention to continue for pleasure the participation in the swimming are also important. Likewise, the motivational climate is another determining factor to take into account and that could affect the results. The motivational climate can have a different impact on adolescents' responses to stress, causing both physiologic and psychological stress responses or reducing the performance-related stressors (Hogue et al, 2017; Jiménez et al., 2019; Kim et al., 2021).

However, we have not identified studies that address the use of a complex assessment system able to measure the mental and biochemical parameters relevant in determining the individual reactivity of swimmers to the effort in training and competitions and able to facilitate the correct management of swimmers' individual preparation depending on stress level.

The aim of the research was to identify the particularities of young swimmers' body adaptation to the stimuli of stress produced by the physical and mental efforts in training and competitive activities.

\section{Materials \& Methods}

\section{Participants}

Six athletes aged 12 to 16 years specialized in $100 \mathrm{~m}$ event - different styles (3 juniors, 14-16 years: 2 boys - butterfly, breaststroke and one girl - backstroke; 3 cadets, 12-14 years: one boy backstroke and 2 girls - front crawl stroke), with a swimming experience of more than 6 years, selected from the entire groupon performance criterion (they ranked in the top 10 in the finals of the National Swimming Championships. The swimmers had the height of $162.9 \pm 3.78 \mathrm{~cm}$, body mass $50.8 \pm 4.24 \mathrm{~kg}$, arm span $167.6 \pm 4.40 \mathrm{~cm}$ and active mass $86.08 \pm 1.00 \%$. The individual competitive tests included in the competition calendar of the Romanian Swimming and Modern 
157 Pentathlon Federation depend on the age category: cadets 12 years (girls and boys) and 13-14

158

159

160

161

162

163

164

165

166

167

168

169

170

171

172

173

174

175

176

177

178

179

180

181

182

183

184

185

186

187

188

189

190

191

192

193

194

195

196

years (boys), 13 years (girls) and juniors 15-16 years (boys) and 14-15 years (girls).

The experimental study was approved by University of Pitesti Ethics Committee for the Doctoral School "Science of Sport and Physical Education" in accordance with the Ethical Standards of the Helsinki Declaration (ecbr5-03-2020). The subjects gave written consent to the study in accordance with the recommendations of the Ethical principles of psychologists (e.g. Meyer, 1988) and Biomedical Research Ethics Committees (e.g. WHO Regional, 2000). Given their age, the subjects had also a written consent signed by their parents regarding their participation to the research.

\section{Methods}

The evaluation of athletes' mental state following up the training and competition stimuli was made by means of four standardized tests taken over from the specialized literature (Cohen et al., 1988; Cohen and Williamson, 1988; Woodman and Hardy, 2003; Judge et al., 2016; Britton et al., 2017).

Two tests were used to measure the perception of stress regarding the stimuli associated to workouts and competitions: Test 1 (TY1), Cohen \& Williamson Test (CWT, 1988) formed of 14 items with 5 response scales, for measuring the degree to which situations in a person's life are assessed as stressful, exploring the subjective experience of stress: low level $<25$ points; average

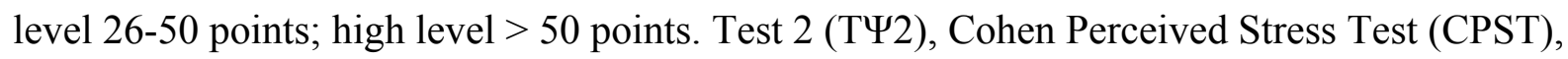
formed of 10 items with 5 response scales, for determining the stress perceived in the last month, ranking feelings and thoughts in relation to the activities carried out: low level $<13$ points; average level 13-20 points; high level $>20$ points.

The following tests were given to determine the competition anxiety: Test 3 (TY3), Sport Competition Anxiety Test (SCAT) - a questionnaire specific to the competitive activity, which assesses the anxiety and includes 15 items with 3 response scales: low level $<17$ points; medium

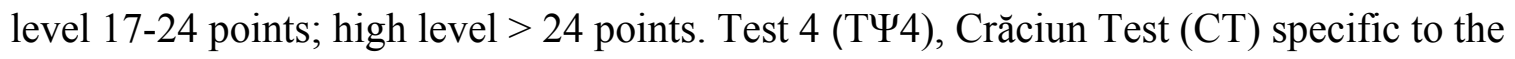
competitive activity, evaluates the anxiety on 3 levels: somatic, cognitive and self-confidence; this test is formed of 9 items with 4 response scales: low level $<4$ points; average level 4-8 points; high level $>8$ points. The test highlights the cognitive anxiety (questions $(\mathrm{Q})-3,6,8$ ), somatic anxiety $(\mathrm{Q}-2,4,7)$ and self-confidence $(\mathrm{Q}-1,5,9)$ (e.g. Crăciun, 2012).

The method of determining the stress level by means of biochemical analyses was applied during workouts, in different periods of preparation, but also in competitions. The biochemical assessment by the technique of blood collecting from the arm was performed in basal stage (before the start of the preparatory period, $8.00 \mathrm{a} . \mathrm{m}$.) and in the competitive period ( 5 minutes after the end of the individual event, between 08:00 and 16:00 o'clock, except for the athletes A5 and A6 - between 18:00 and 21:00 o'clock), before and after effort. Venous blood was collected directly in special vacutainers for each type of analysis. The amount of blood collected for each parameter was: hematological parameters ( $\mathrm{VSH}-1.6 \mathrm{ml})$, blood count $(2 \mathrm{ml})$; biochemical parameters (Blood glucose and Total serum cholesterol - $6 \mathrm{ml}$ ); hormone/endocrine markers: plasma catecholamines (epinephrine, norepinephrine, dopamine - $4 \mathrm{ml}$ ), prolactin and cortisol (6

Peer) reviewing PDF | (2021:01:57290:3:0:NEW 23 May 2021) 
197

198

199

200

201

202

203

204

205

206

207

208

209

210

211

212

213

214

215

216

217

218

219

220

221

222

223

224

225

226

227

228

229

230

231

232

233

234

235

236

$\mathrm{ml})$. The amount of blood collected from an athlete before effort was $19.6 \mathrm{ml}$ and the same amount was collected after effort (total amount of $39.2 \mathrm{ml} /$ athlete). The basal analyses and the analyses during competition determined the metabolic parameters - lymphocytes (\%) and blood glucose $(\mathrm{mg} / \mathrm{dl})$ - and the endocrine parameters: norepinephrine ( $\mathrm{mmol} / \mathrm{l})$, prolactin $(\mathrm{ng} / \mathrm{ml})$ and cortisol $(\mu \mathrm{g} / \mathrm{dl})$ before the effort made in competition and immediately after effort, in minute 5 . These biochemical parameters were selected because they showed changes above normal values after the competition effort (Soultanakis and Platanou, 2008; Papadopoulos et al., 2014; Zacca et al., 2019).

To determine the anaerobic capacity in training, the capillary blood test was used for measuring the blood lactate $\left(\mathrm{mmol} \cdot \mathrm{L}^{-1}\right)$ and blood glucose $\left(\mathrm{mmol} \cdot \mathrm{L}^{-1}\right)$ before effort and after effort, when the 8x100 m specialized swimming stroke was used (motor test - MT1), start at $150 \mathrm{sec}$, with a pause of 1 min approximately; the competition events were split 2x50 m (MT2), with 5 sec pause; in the $5^{\text {th }}$ and $15^{\text {th }}$ minute after effort for the assessment of the quality of the recovery capacity after effort. The Lactate Pro portable analyzer with Lactate Pro Test Strips was used to determine the blood lactate, which was generally less than $+/-2.0 \mathrm{mM}$ over the physiological range of 1.0-18.0 $\mathrm{mM}$ (range of mean difference: $-0.06 \mathrm{mM}$ to $0.52 \mathrm{mM}$ ), Mean Squared Error and correction for Bias indicated that both the Edge and Xpress had low 'total' error ( 0-2 mM) for lactate concentrations $<15 \mathrm{mM}$ (e.g. Bonaventura et al., 2015); the blood glucose was determined by means of the portable analyzer Accu-Chek Performa Nano glucometer with AccuChek Performa test strips, Detection limit (lowest value displayed): $10 \mathrm{mg} / \mathrm{dL}(0.6 \mathrm{mmol} / \mathrm{L})$ for the test strip, System measurement range: $10-600 \mathrm{mg} / \mathrm{dL}(0.6-33.3 \mathrm{mmol} / \mathrm{L})$, Sample size: 0.6 $\mu \mathrm{L}$, Test time: 5 seconds (Şalgău, 2017; Ferreira et al., 2019; Arsoniadis et al., 2020a, 2020b). The time in the motor tests was measured with the help of the Professional Timer Stopwatch, Digital Sports Stopwatch with Countdown Timer, 100 Lap Memory, 0.001 Second Timing (water resistant, multi-functional stopwatch for swimming, running, training). The determination of the training times in the different effort zones was made following the $\mathrm{T} 30$ test. After this test, the average per $100 \mathrm{~m}$ was calculated; this one is the time in the R2 effort zone - threshold resistance. After establishing the average per $100 \mathrm{~m}$ (R2 zone), the rest of the effort zones are calculated. The calculation modality is also described by W. Ernest Maglischo (Maglischo, 1993; Zacca et al., 2019).

\section{Experimental Design}

The research was carried out throughout a training macrocycle formed of 4 mesocycles (MC).

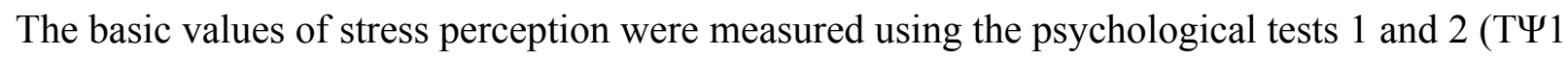
and T $\Psi 2$ ); biochemical analysis was used by collecting metabolic and hormonal venous blood tests at the beginning of the training (testing - T1), after two weeks of holiday. Given that the subjects correspond to the two categories of competitive age (juniors 14-16 years and cadets 1214 years), the planning of the effort volume was made differently (table 1):

\section{Insert here table 1}

-stage I (E1), general: 4 weeks - junior and 5 weeks - cadets. The perception of stress in training

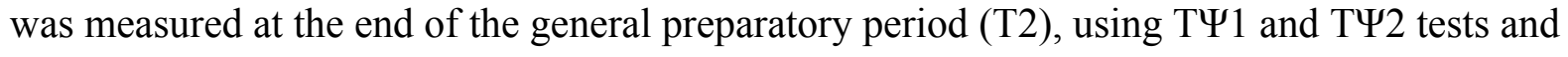


237 biochemical analyses by collecting capillary blood tests (La and Glu) before and after effort in 238 the $5^{\text {th }}$ and $15^{\text {th }}$ minute, in parallel with the motor tests of training $8 \times 100 \mathrm{~m}$ (B\&MT1) (e.g. 239 Nunes et al., 2020).

240 - stage II (E2), specific: 3 weeks - junior and 5 weeks - cadets. The perception of stress was 241 measured at the end of the period(T3); biochemical analyses were made by collecting capillary 242 blood tests (La and Glu) before and after effort in the minutes 5 and 15 (B\&MT1), in parallel 243 with the motor tests of training $8 \times 100 \mathrm{~m}$ (e.g. Nunes et al., 2020).

244 - stage III (E3), pre-competitive (2 weeks). Capillary blood biochemical analyses (La and Glu) 245 were collected before and after effort in the minutes 5 and 15 (B\&MT2), in parallel with the 246 motor tests of training $2 \times 50 \mathrm{~m}$ (e.g. Nunes et al., 2020).

247 - stage IV (E4), competitive (1 week). Measurement of stress perception (tests 1 and 2) and 248 competitive anxiety (tests 3 and 4) (T4), biochemical analyses were made by collecting venous 249 blood tests ( $\mathrm{La}$ and Glu) before and after competitive effort in the minutes 5 and 15, $100 \mathrm{~m}$ 250 event, the specialized style.

251 Based on the results of motor tests, biochemical analyses and the physical training model 252 recommended by Maglischo, (1993), weekly models and individualized training models were 253 developed per effort zones, at the beginning and the end of the research.

254 Analysis data

255 All statistical analysis of the study results was performed using the KyPlot, version 5.0, Data 256 Analysis \& Visualization software package (IBM Kyens LabInc., Japan) and SPSS (IBM Co, 257 Armonk, NY, USA), version 23. Descriptive statistics methods were used to calculate median, 258 standard deviation (SD), range, Cohen's d effect size, probability of superiority (PS) (e.g. Fritz et 259 al., 2012), Cronbach`s Alpha, Wilcoxon Signed Rank Test for Paired Data and Friedman Test 260 with Replication were used to compare the means of the parameters studied between tests (e.g. 261 Yoshioka, 2002). Pearson's correlation coefficient was used to examine relations between 262 variables. Statistical significance was set at $\mathrm{p}<0.05$ (e.g. de Winter et al., 2016).

\section{Results}

264 The quantitative results recorded by the subjects during the research are presented, in their 265 dynamics, in the following tables and figures, systematized on the three levels of the research: 266 mental, motor and biochemical, in training and competitions. The qualitative aspects of the 267 results were analyzed at the level of group of subjects (highlighting the common aspects and 268 individual differences of the reactivity of the six subjects) but also at the individual level, 269 interpreting the significance of the dynamics of each monitored indicators.

270 The results of the psychological particularities of stress perception in young swimmers under the 271 influence of stimuli from training and competition are shown in table 2.

\section{Insert here table 2}

273 The results analysis of the stress perceived at CWT presented the distribution of the individual 274 values on a three-level scale related to the low level value (25 points). At the beginning of the 275 research at basal level (T1), the athletes recorded a perception of stress $10 \%$ over the low level. 276 The analysis of the dynamics of the individual values at each stage revealed that all athletes had 
277 progressive increases of the perceived stress in training by $8 \%$ at T2 compared with T1 ( $p<$

$2780.05)$ and by $12 \%$ at T3 - with T2 $(p>0.05)$. At the end of the research, at T4 compared with T1, 279 the athletes showed an increase by $34 \%$ in the perception of stress $(p>0.05)$. Regarding the 280 adaptation of athletes' body to stress stimuli in training and competitions, there are significant 281 differences at $p<0.05$, which confirms the effectiveness of planning the effort parameters in 282 training.

283 The dynamics of the perception of the individual stress in training was made with the help of 284 CPST. The distribution of the individual values was achieved on a three-level scale. When the

285

286

287

288

289

290

291

292

293

294

295

296

297

298

299

300

301

302

303

304

305

306

307

308

309

310

311

312

313

314

315

research started (T1), the athletes presented do perception of the stress by $23 \%$ up to the average level of stress. The dynamics of the individual values at each stage showed that all athletes have progressive increases of stress perception in training sessions by $6 \%$ in T2 compared with T1 ( $p$ $>0.05)$ and by $27.5 \%$ in T3 - cu T2 $(p>0.05)$. At research ending, the athletes presented - in T4 compared with T1 - an increase by $37.5 \%$ of the perceived stress $(p>0.05)$. It refers to the concerns and feelings of the last month regarding the passing of the middle school graduation national exam. As for the athletes' body adaptation to the stimuli of stress in workouts and competitions, significant differences are observed at $p<0.05$, which validates the proper management of effort parameters in training.

The assessment of the competitive anxiety was performed by using SCAT and CT, in the Junior National Championships, approximately one hour after the end of the event.

The analysis of the results regarding the perceived stress in competition (SCAT) showed the distribution of the individual values on a three-level scale. The competitive anxiety values reveal an average level of anxiety. Comparing the individual results, it was observed that 2 athletes (A2, A4) had low values of anxiety, other 2 athletes $(A 3, A 6)$ had a medium level and the other two (A1, A5) - high anxiety.

The CT test was used as a basis for improving and detailing the criteria of assessment of the modern diagnosis regarding the competitive anxiety. Detailing the anxiety assessment scale in three levels, at each criterion, made possible a more in-depth knowledge of the competitive anxiety of young swimmers. The results of the analysis highlighted a competitive anxiety increased by $70 \%$ at cognitive and self-confidence; the less affected by the competition was the somatic anxiety with $54 \%$, at the low level. The comparative analysis between the indicators of SCAT and CT tests reveals significant differences at $p<0.05$ and $p<0.01$ within the tests. The correlation of the individual values between the test indicators shows that at the low level of anxiety SCAT corresponds more to the self-confidence sphere, at medium level to the cognitive and somatic sphere; at high level - to the cognitive sphere. These strong connections show the influence of the competitive stress stimuli on the adaptation of athletes' body.

Figure 1 presents the volume of the means of training in the young swimmers at the beginning (E1, general stage) and the end (E3, pre-competitive stage) of the research according to the specialized styles.

\section{Insert here figure 1}

Peer] reviewing PDF | (2021:01:57290:3:0:NEW 23 May 2021) 
316 The comparative analysis highlights the motor particularities related to the content of the 317 individual training plans. It was noticed the decrease of the volume by $5-6 \%$ except for the cadet 318 swimmers (12-14 years old) specialized in front crawl stroke, who had a volume of $26 \%$ of warm 319 up at the beginning of the research and $6 \%$ at the end of the research. In the research final part, it

320

321

322

323

324

325

326

327

328

329

330

331

332

333

334

335

336

337

338

339

340

341

342

343

344

345

346

347

348

349

350

351

352

353

354

355

356 was found out that $11-13 \%$ technique exercises (TE) for backstroke swimmers and $6 \%$ for front crawl stroke were included in the content of the training means; these exercises were not necessary for the butterfly stroke and breaststroke swimmers, given the style characteristics. The workouts for legs were increased by 1-3\%; the increase for the cadet swimmers (12-14 years old) in final period was by $21 \%$, although they did not have these workouts initially. The means of relaxation had $6 \%$ in both stages, with small changes by $\pm 1-3 \%$ at the end.

Concerning the distribution of the specific volume per effort zones in training, it was observed that the backstroke style swimmers (A1 and A4) were specialized in the medium and long events ( $400 \mathrm{~m}$ and $800 \mathrm{~m}$ freestyle and $200 \mathrm{~m}$ backstroke). At the beginning of the research, the athlete A1 (junior, 16-year-old) worked with $65 \%$ of the training volume, namely $12 \%$ on S2 zone (lactate production) and $53 \%$ on R1 zone (basic endurance) with a decrease of $10 \%$ at the end (S2 - 25\% and R1 - 31\%). The athlete A4 (cadet, 13-year-old) worked $62 \%$ initially, with $31 \%$ on R1 and R2 zones (threshold resistance) and a decrease of $6 \%$ at the end (R1 and R2 -28\%) (fig. 1a and b). The junior swimmers (A2, 15-year-old - butterfly and A3, 14-year-old breaststroke) were specialized in $100 \mathrm{~m}$ and $200 \mathrm{~m}$ events. Both athletes worked with $66 \%$ of the training volume at the beginning and the end of the research, namely with $23 \%$ on R1 and $43 \%$ on R2 at the beginning and $29 \%$ on R1 and $37 \%$ on R2 at the end (fig. 1c). The cadets (A5, 12year-old and A6, 12-year-old) were specialized in the $50 \mathrm{~m}, 100 \mathrm{~m}, 200 \mathrm{~m}$ events - freestyle and backstroke. Both athletes worked with $68 \%$ of the training volume at the beginning of the research, namely $3 \%$ on S1 (lactate tolerance), $13 \%$ on S2 and $52 \%$ on R1; at the end their decrease was by $7 \%$, namely $12 \%$ on S1, $25 \%$ on S2 and $24 \%$ on R1 (fig. 1d).

The results achieved by athletes in the motor tests that included standardized training exercises are shown in table no 3 .

\section{Insert here table 3}

The blood lactate (La) and blood glucose (Glu) were the metabolic biochemical indicators monitored during training sessions in order to highlight the relationship between effort-fatiguerecovery. The anaerobic capacity was monitored by the value of La (lactate). At the level of the group, an ascending dynamic of the La accumulated following the specific effort was observed, with peaks in E2 period, when both volume and intensity of the effort were high. In this period, it was programmed to increase the resistance to La accumulations, in pre-effort by $0.04 \mathrm{mmol} \cdot \mathrm{L}^{-1}$, after $5 \mathrm{~min}$ post-effort by $3.8 \mathrm{mmol} \cdot \mathrm{L}^{-1}$ and after $15 \mathrm{~min}$ post-effort by $2.63 \mathrm{mmol} \cdot \mathrm{L}^{-1}(p<$ $0.01)$. In $\mathrm{E} 3$ there are decreases compared to $\mathrm{E} 2$, which reflects an adaptation to the specific effort, an increase of the anaerobic capacity by $0.09 \mathrm{mmol} \cdot \mathrm{L}^{-1}$ in pre-effort by $1.48 \mathrm{mmol} \cdot \mathrm{L}^{-1}$ after $5 \mathrm{~min}$ post-effort and by $1.11 \mathrm{mmol} \cdot \mathrm{L}^{-1}(p<0.01)$ at $15 \mathrm{~min}$ post-effort. The values of Glu showed the following values in E2: decreases by $2 \mathrm{mmol} \cdot \mathrm{L}^{-1}$ in pre-effort, increases by 21.2 $\mathrm{mmol} \cdot \mathrm{L}^{-1}$ in $5 \mathrm{~min}$ post-effort and by $11.3 \mathrm{mmol} \cdot \mathrm{L}^{-1}$ in $15 \mathrm{~min}$ post-effort $(\mathrm{p}<0.05)$. There are also decreases in $\mathrm{E} 3$ by $5.83 \mathrm{mmol} \cdot \mathrm{L}^{-1}$ in pre-effort, by $19.2 \mathrm{mmol} \cdot \mathrm{L}^{-1}$ in 5 min post- effort, 
357

358

359

360

361

362

363

364

365

366

367

368

369

370

371

372

373

374

375

376

377

378

379

380

381

382

383

384

385

386

387

388

389

390

391

392

393

394

395

396

and by $12.8 \mathrm{mmol} \cdot \mathrm{L}^{-1}$ in $15 \mathrm{~min}$ post-effort, which showed the impact of the effort on the body and on the ability to recover after effort $(p<0.05)$. The results of the training speed calculations highlight the increase by $0.03 \mathrm{~m} \cdot \mathrm{s}^{-1}(1.24 \mathrm{sec})$ at the $8 \times 100 \mathrm{~m}$ motor test between E1 and E2 and by $0.16 \mathrm{~m} \cdot \mathrm{s}^{-1}(7.29 \mathrm{sec})$ at $2 \times 50 \mathrm{~m}$ test in E3. The comparison with the values with E1, posteffort $5 \mathrm{~min}$ blood La and pre-effort blood Glu, the others are small. The performances of the motor tests (MT) were compared to the biochemical parameters, which allowed on the one hand the recording of the biochemical reactivity to the specific effort, respectively the adaptation of the body to effort, and on the other hand the establishment of the aerobic threshold speed and the calculation of the individualized training speeds in order to optimize the performance capacity from one training period to another.

The results of the metabolic and hormonal biochemical indicatorsduring competition are listed in table no 4 . The analysis was based on the premise that any disturbance in hormones functioningcauses the diminution of energy efficiency and the decrease of body resistance to stress, which has a negative impact on the elite athletes. The metabolic and hormonal parameters were investigated in basal stage (T1), depending on effort (pre and post-effort) (T4) and mental stress of the competition for analyzing objectively the efficiency of athletes in relation to their individualized training level.

\section{Insert here table 4}

The comparative analysis of the metabolic biochemical parametersin Lymphocytes (\%) highlights an increase by $4 \%$ in pre-effort and by $13 \%$ post-effort $(p>0.05)$. In terms of Glu $(\mathrm{mg} / \mathrm{dl})$, the parameters in basalstage andin pre-effort are within the normalreference limits; the glucose concentrationin post-effort increases by $35 \%$ related to the basal level $(p<0.05)$. Regarding the hormonal biochemical indicators in Norepinephrine ( $\mathrm{mmol} / \mathrm{l})$, both in basal and pre-effort period, these ones have normal values with a decrease by $46 \%$ related to the basal stage and an increase by $93 \%$ over the normal reference limit in post-effort $(p<0.01)$. The Prolactin hormone shows an increase by $37 \%$ in pre-effort and by $117 \%$ in post-effort; all measured values are within the normal reference limits $(p<0.05)$; the Cortisol hormone $(\mu \mathrm{g} / \mathrm{dl})$ has a decrease by $12 \%$ in pre-effort and an increase by $27 \%$ in post-effort $(p<0.05)$. The individual results of the athletes showed that $50 \%$ of the metabolic resultsare above the maximum values at the 2 indicators, mainly post-effort (42\%), which determined an individualized carbohydrate recovery anda new approach to effort and recovery, through changes in training intensities, in line with the demands of the competition, associated with intensifications of the post-effort recovery meant to reduce the risk of exceeding the maximum values. The individual results of the athletes showed that $17 \%$ of the hormonal results are over the maximum values at the 3 indicators, mainly post-effort (14\%). This fact determined the rethinking of the training based on the premise that the effect of the stress on the brain depend on the stress hormones (cortisol, catecholamines, prolactin), which have the ability to cross the blood-brain barrier and impair the cognitive processes: attention, memory, decision making. The results of the correlation between the metabolic, biochemical, mental and motor indicators in training are shown in table no 5. 
397

398

399

400

401

402

403

404

405

406

407

408

409

410

411

412

413

414

415

416

417

418

419

420

421

422

423

424

425

426

427

428

429

430

431

432

433

434

435

\section{Insert here table 5}

Spearman's correlative analysis of the stimuli of the stress induced in training sessions

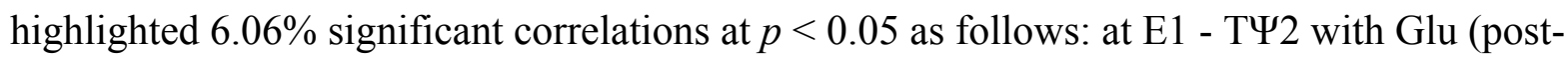
effort, $5 \mathrm{~min}$ ); at E2 -MT1 with Glu (pre-effort) and T $\Psi 1$ with La (post-effort) at the $5^{\text {th }}$ and $15^{\text {th }}$ minute. Regarding the association of the correlation degree between variables at each tested stage, it is observed that 66 correlations were made, in which $75.8 \%$ have strong connections (9.1\%), moderate connections (30.3\%) and poor connections $(36.4 \%)$ while $24.2 \%$ have very weak or non-existent connections. Thus, we find out that there is an interdependent relationship between the correlated variables determined in the training sessions and the efficiency of the implemented technology. At the level of the individual values analyzed by us, the correlations of this type determined the correct management of the effort for the permanent adaptation and readaptation of the athletes in various periods of training.

\section{Insert here table 6}

Regarding the Spearman's correlative analysis of the competition-induced stress (table 6), a

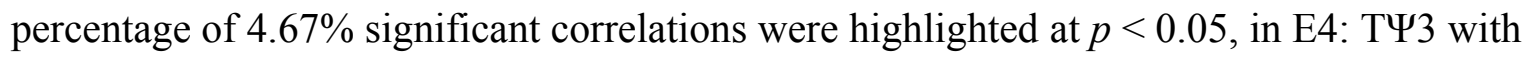

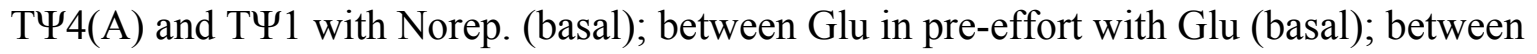
Norep. with TY4 (CT) and the performance in competition; Cortisol with Limf. (basal); between Limf. post-effort with Prolac. (basal) and Limf. post-effort with Limf (basal). As for the association of the correlation degree between the competitive stress perception variables, the result of the competition performance and the biochemical parameters in basal, pre-effort and post effort stages, one can notice that 171 correlations were made, out of which $70.2 \%$ have poor connections $(43.3 \%)$, moderate $(20.5 \%)$ and strong ones $(6.4 \%)$ while $29.8 \%$ have very poor or non-existent connections. In terms of effort-fatigue-recovery relationship, the significant correlations highlight the interdependence between the mental and physiological stress in competition and the biochemical data of the hormonal and metabolic parameters. Therefore, these correlations must be used to determine the physiological stress induced by the competition set as a goal and to create objective premises for the individualization of the post-competitive recovery.

\section{Discussion}

One of the factors that favors the increase of swimming performance is the adaptation and readaptation of the body to the stimuli of physical and mental stress in training and competitions. The main objectives underlying the investigation of these adaptation particularities refer to: monitoring of mental, motor and biochemical indicators and planning the volume of training effort; measuring the perception of stress and competitive anxiety in accordance with the research stages and training periods; distribution of the specific volume by effort zones in training at the beginning and end of the research, depending on the specialized style; analysis of lactate and blood glucose concentration by evaluating the motor tests in different training stages; comparative analysis of the hormonal and metabolic biochemical parameters in competitions; correlative analysis of stimuli of the stress induced in training and competitions. 
436 A major tool in conducting the research was monitoring the mental, motor and biochemical 437 indicators and planning the training effort volume. There are studies that support the monitoring 438 of the physiological, kinematic and performance changes induced by the swimming training in 439 the regional athletes of the age group; the extrinsic factors (related to environment conditions, 440 such as development and training program) can be improved by monitoring their implementation 441 over time, to quantify changes and contributions of energetic, technique and anthropometric 442 profiles across the first training macrocycle (16-week) in a traditional 3-peak swimming season 443 (Bourdon et al., 2017; Tucher et al., 2019; Zacca at al., 2018; 2019; Morais, et al., 2013, 2014, 444 2020). It was also found out an increase of swimmers' performance in $25 \mathrm{~m}$ and $50 \mathrm{~m}$ in the best 445 stroke technique, at critical speed, in the biochemical and anthropometric parameters along the 44628 weeks of training. All of these parameters can be used to monitor the training and 447 performance throughout a season without using sophisticated equipment (e.g. Dias et al., 2012). 448 Modeling the progress of performances can serve as a tool of detecting the talents. The effect of 449

450

451

452

453

454

455

456

457

458

459

460

461

462

463

464

465

466

467

468

469

470

471

472

473

474

475 growth during a summer break on the biomechanical profile of talented swimmers was also studied (Dormehl et al., 2016; Moreira et al., 2014). Other studies focused on the monitoring of the swimming training program on the state of muscular oxygenation in short distance swimming (e.g. Jones et al., 2018). The monitoring of stress and recovery states in elite swimmers before championships could be used as indicator of training status in athletes (e.g. Nicolas et al., 2019). The results of the mental, motor and biochemical tests were analyzed by comparison and correlation in order to objectively monitor the individual response to the stimuli of training and competition. Psychological tests showed increases and changes in the mental behavior of athletes during training by $34 \%$ at CWT and by $37.5 \%$ at CPST; an average level of stress at SCAT and $70 \%$ stress in cognitive and self-confidence at CT were found out in competition. An important feature in the evaluation of stress was the analysis of the mental state following the stimuli from training and competition. Several works analyze the following issues: fluctuations of anxiety and self-confidence in competition, measuring these variables before, during and after competition (e.g. Butt et al., 2003); the development and validation of a sport-specific measure of cognitive and somatic trait anxiety (e.g. Smith et al., 2007); usefulness of heart rate variability (HRV) analyses as non-invasive means of quantifying the cardiac autonomic regulation during the precompetitive anxiety situations in swimmers (Blásquez et al., 2009); measurement of cognitive and somatic competitive anxiety and self-confidence (e.g. Crăciun, 2012); determining the relationship of competitive anxiety (cognitive and somatic) between some variables (age, weight, height and body mass index) of male elite swimmers (e.g. Nikseresht et al., 2017); investigating the nature of the relationship between precompetitive anxiety state (CSAI-2C), subjective (race position) and objective (satisfaction) performance outcomes, and self-rated causal attributions (CDS-IIC) for performance in competitive child swimmers (e.g. Polman et al., 2007), but also the avoidance of stress occurrence (Ware \& Matthay, 2000; Grosu et al., 2015; Iurea \& Safta, 2018).

Regarding the distribution of the specific volume per effort zones in training, in the case of the backstroke specialized swimmers, it was observed that the swimmer A1 (junior) worked at the 
476 beginning of the research with $65 \%$ of the training volume and a decrease by $10 \%$ at the end.

477 The swimmer A4 (cadet) worked initially with $62 \%$ of the training volume and a decrease by $6 \%$

478 at the end. The junior swimmers (A2 - butterfly and A3 - breaststroke) worked with $66 \%$ of the

479 training volume at the beginning and the end of the research. The cadet swimmers (A5 and A6) 480 front crawl stroke and backstroke - worked with $68 \%$ of the training volume at the beginning of 481 the research but they had a decrease by $7 \%$ at the end. According to the individual results of the 482 biochemical indicators, the distribution of the 6 effort zones in the weekly training plan was 483 made as follows: R2 and R3 training zones were planned so that the swimmers have 34-56 hours

484

485

486

487

488

489

490

491

492

493

494

495

496

497

498

499

500

501

502

503

504

505

506

507

508

509

510

511

512

513

514

515 for recovery before using again the same zones. A series of S1 (lactate tolerance) and 2 series of S2 (lactate production) were placed at least 24 hours of recovery after the Resistance series R2 and R3. The S3 (Power) was positioned before the training day in the R2 effort zone so that enough glycogen could be found in the muscles to support the fast-swimming speed (e.g. Maglischo, 1993). The results of the biochemical tests in training highlighted an ascending dynamic of the La accumulated after a specific effort, with peaks in E2 period and decreases in E3 compared with E2, which reflects an adaptation to the specific effort and an increase in anaerobic capacity. The highlighted Glu values decrease in pre-effort and increase in the $5^{\text {th }}$ and $15^{\text {th }}$ minute post-effort in E2; concerning E3, the values decreased in pre-effort and post-effort the $5^{\text {th }}$ and $15^{\text {th }}$ minute, which showed the impact of the effort on the body and the capacity of recovery after the effort. Physical effort with an intensity over $80 \%$ can increase blood glucose level by discharging epinephrine (adrenaline), which causes the elimination of glucose from the liver. The results of the biochemical tests during workouts in parallel with the motor tests performances show that swimming training causes increases of blood glucose due to the intense efforts and stress to which the body is subjected (Kirschbaum and Hellhammer, 1989; Dimitriou et al., 2002; Afshari et al., 2014; Jiménez et al., 2012).

The individual metabolic results of the competing swimmers were by $50 \%$ above the maximum values, mainly after effort (42\%); the hormonal results exceeded by $17 \%$ the maximum values, mostly after effort (14\%). As for the results of the hormonal parameters determined before the competitive effort, they have lower values than the ones recorded in basal conditions for noreprinephrine but after the effort made in competition they increased, which showed that stress and intense effort cause increases in norepinephrine, without exceeding the normal values.

Prolactin increased compared to baseline conditions; it also increased before or after competition, without going beyond normal maximum values. As for cortisol, before the competitive effort the subjects had lower values than the ones recorded in baseline conditions; after the effort made in competition, there were increases of cortisol level without exceeding the values recorded in basal conditions, which highlights the fact that the stress and intense effort led to increases in this indicator (Kanaley et al., 2001; Soria et al., 2015; Caracsso et al., 2007;

Crewther et al., 2013).

The correlative analysis of stress-induced stimuli during training sessions revealed $6.06 \%$ significant correlations at $p<0.05$ while in competitions there are $4.67 \%$ significant correlations at $p<0.05$ (e.g. de Winter et al., 2016). The research results determined that there are 
516 differences in the cognitive anxiety level shown by different categories of swimmers. These 517 differences were related to the qualification level. This study also showed that there is a negative 518 correlation between cognitive anxiety and performance (e.g. Parnabas et al., 2015).

519 An important indicator in the physical effort orientation in training was the distribution of the 520 specific volume on effort zones in different periods of training, depending on the results of the 521 mental, motor and biochemical tests andon the observation protocols performed. Thus, 522 corrections were made to the training plan for each athlete, at motor, biochemical and mental 523 level. For example, in the case of the athlete A4 (butterfly stroke) with low lactate level (5.3 $524 \mathrm{mmoli} / \mathrm{l}$ in the preparatory period) and good results, a well-developed aerobic system was 525 reached. Because high values of lactate of $10.3 \mathrm{mmol} / \mathrm{l}$ were recorded after the motor tests

526

527

528

529

530

531

532

533

534

535

536

537

538

539

540

541

542

543

544

545

546

547

548

549

550

551

552

553

554

555 performed during the specific training period and a value of $10.9 \mathrm{mmol} / 1$ in the pre-competitive period, the swimming was performed in effort zones of low intensities with short pauses (aerobic effort) but using mainly the backstroke. On the basis of the notes included in the observation protocol, two weekly training sessions on Ergosim Conditions Simulator were introduced to correct mistakes because technical mistakes were identified in the movement of arms in backstroke (Salgau, 2008; Mihăilescu and Dubiț, 2015). At mental level, psychological counseling was introduced once a week given that the swimmers manifested average values of stress caused both by family problems and demands of the specific and competitive training. In order to be able to restore energy reserves, the glucose values were measured after effort because the swimmers may also have decreases in the reserves of glycogen (which produces energy); so, if necessary, a hyperglycemic diet was recommended.

While carrying out the research, it was taken into account the observance of the four fatigue stages as presented in the vision of the physiologist Ulmeanu FC, (1967): oscillating fatigue (incomplete recovery), harmonious fatigue (specific to athletes), discordant fatigue (physical and mental fatigue), pathological fatigue (exhaustion) (Ulmeanu, 1967; Sargent et al., 2014). In the experimentalmethodological approach regarding the optimization of sports performance, it was taken into consideration the observance of the four phases of overcompensation as presented in the specialized literature (e.g. Bompa, 2002).

The results of the mental tests were in a functional relationship with the biochemical ones, which showed large accumulations of lactate in the specific period and decreases in the pre-competitive period. The dynamics of the lactate levels along different periods reflected the functional stress, corresponding to the mental one. Regardless of the type/nature of the test used (motor, mental or biochemical one) similar validity criteria must be ensured, so that the test provides useful and associative informationon the current or future performances (Smith et al., 2002; RodríguezZamora et al., 2012; Whdan N. 2014; Mihăilescu \& Dubiţ, 2015;). Performing an effective endurance training requires an exact monitoring of the changes in the aerobic and anaerobic capacity, as well as a careful evaluation of the training speeds by means of some biochemical blood tests. The blood tests can be used to improve the training in four ways: establishing the training speeds, recording the training progress, diagnosing the weaknesses of the training programs and comparing the potential of a swimmer with that potential of another 
556 swimmer in order to achieve high performances. The training volume in swimming is usually

557

558

559

560

561

562

563

564

565

566

567

568

569

570

571

572

573

574

575

576

577

578

579

580

581

582

583

584

585

586

587

588

589

590

591

592

593

594

595

very large compared to the relatively short competition time. The training at high intensity intervals has been shown to improve the performance in a rather brief period (Sperlich et al., 2010; Arsoniadis et al., 2017; Șalgău, 2017; Moser et al., 2020).

The anaerobic threshold tests measure the concentration of lactate in timed repetitions series, swimming at progressive speeds. The lactate concentration depending on the swimming speed shows the results of one of the most used blood tests (Bitang and Dulceanu, 2014; Nikitakis et al., 2019; Arsoniadis et al., 2020).

The methodology used at this age and in this sport, at the level of the individual values, was validated on the basis of the quantitative and qualitative analysis of the research results, opening opportunity windows for larger studies conducted nationally and internationally on swimming and other sport branches too.

\section{Conclusions}

The research results enable us to state that higher performance in swimming can be reached if the training is based on monitoring (of the motor, mental and biochemical indicators), planning (of the training effort volume per effort zones), assessment (of swimmers' individual reactivity to effort) and control.

The correlation of the information obtained by biochemical investigations with the psychological profile of the swimmers reflects their biological adaptation to training and competition effort and helps to improve their competitive performance.

The research demonstrated that performance in swimming can be increased by adaptation of the young swimmers' body to the stimuli of physical and mental stress in training and competitions.

\section{Limitations of the study}

This is pilot study; the research is experimental type but was operationalized by analyzing the individual results, fact that represents a limit of the research. The results obtained have relevance and scientific significance only at the level of the research subjects and cannot be generalized. Results must be considered as new knowledge to be confirmed or refuted in longitudinal research works. However, they have a great practical applicability for both swimming and other sports, where ensuring the effort-fatigue-recovery relationships decisive in achieving sports performance. The research analyzed the individual particularities of training and the adaptive changes to the training and competition effort of the young swimmers in different swimming stroke. The small number of subjects participating in the researches is explained by the impossibility of individualized monitoring and recording of the data that were methodologically operated by other coaches during training. That is why we appealed to only one coach of the club, who worked directly with the respective swimmers. The hormonal tests were collected according to the order of participation in competition: the first 4 swimmers from 08:00 to 16:00 o'clock and the last 2 swimmers from 18:00 to 21:00 o'clock, when the circadian cycles decreased; this must be taken into account in order to reproduce this study in the future. Because there is no data base with values of the two categories of biochemical parameters that we used, the analysis of the research results was made only against the basic benchmarks of laboratories

Peer) reviewing PDF | (2021:01:57290:3:0:NEW 23 May 2021) 
596 and related to the individual dynamics of those values, throughout a training macrocycle, without 597 reference to particularities of the values in elite athletes generally and swimmers particularly.

598 Acknowledgements

599 This article is part of the planned scientific paper „Relationship between effort-fatigue - stress, 600 limiting or favoring factor in increasing the performance capacity" in the Doctoral School of 601 Physical Education and Sports Science, CSUD University of Pitești (contract no 941/2013).

602 We express our gratitude to the following personalities who gave us a kind support for the 603 achievement of this research: Professor Catalina Poiana, PhD, Senior medical specialist of 604 endocrinology, Head of Endocrinology Department - "C.I. Parhon" National Institute of 605 Endocrinology of Bucharest; Prorector of "Carol Davila" University of Medicine and Pharmacy 606 of Bucharest; Professor Graziela Vajiala, PhD - "Spiru Haret" University of Bucharest, 607 Biochemistry discipline; Scientific researcher $1^{\text {st }}$ rank; President of ANAD România; President of

608 Council of Europe Advisory Group on Educational Issues; Daniela Mihai, teacher, PhD student, 609 LPS Pitesti, Chemistry Discipline, Deputy Director.

610 We also thank the lecture Mihai Ilie, $P h D$ and the athletes who participated in this research for 611 their agreement, support and collaboration.

\section{References}

613 Afshari L, Mohammadi S, Shakerian S, Amani R. 2014. The Effect of Oral Carbohydrate

614 Solutions on the Performance of Swimmers. Annals of Applied Sport Science 2(3):13-22.

615 Anshel MH. 2001. Qualitative validation of a model for coping with acute stress in sport.

616 Journal of Sport Behavior 24(3):223-246.

617 Arsoniadis GG, Botonis PG, Nikitakis IS, Kalokiris D, Toubekis AG. 2017. Effects of

618 Successive Annual Training on Aerobic Endurance Indices in Young Swimmers. The Open

619 Sports Sciences Journal 10, 214-221 DOI:10.2174/1875399X01710010214.

620 Arsoniadis GG, Nikitakis IS, Botonis PG, Malliaros I, Toubekis AG. 2020a. Validating

621

622

623

624

625

626

627

628

629

630

631

632

633 Physiological and Biomechanical Parameters during Intermittent Swimming at Speed Corresponding to Lactate Concentration of $4 \mathrm{mmol} \cdot \mathrm{L}-1$. Sports $8(2), 23$ DOI: $10.3390 /$ sports 8020023 .

Arsoniadis GG, Nikitakis IS, Botonis PG, Malliaros I, Toubekis AG. 2020b. Verifying Physiological and Biomechanical Parameters during Continuous Swimming at Speed Corresponding to Lactate Threshold. Sports 8(7), 95 DOI:10.3390/sports8070095.

Bonaventura JM, Sharpe K, Knight E, Fuller KL, Tanner RK, Gore CJ. 2015. Reliability and Accuracy of Six Hand-Held Blood Lactate Analysers. Journal of Sports Science and Medicine 14:203-214.

Bădescu V, Galeru O. 2009. Controlling the swimming endurance training through the lactat.pas software. Gymnasium - Scientific Journal of Education, Sports and Health 10(2):37-40.

Bitang V, Dulceanu C. 2014. Computer simulation as factor for improving speed at junior swimmers. Gymnasium - Scientific Journal of Education, Sports and Health 15(2):7-24. 
634 Butt J, Weinberg R, Horn, T. 2003. The intensity and directional interpretation of anxiety:

635

636

637

638

639

640

641

642

643

644

645

646

647

648

649

650

651

652

653

654

655

656

657

658

659

660

661

662

663

664

665

666

667

668

669

670

671

672

fluctuations throughout competition and relationship to performance. The Sport Psychologist 17(1): 35-54 DOI: 10.1123/tsp.17.1.35.

Bompa TO. 2002. Teoria şi metodologia antrenamentului - periodizarea [Theory and Methodology of Training - Periodization]. Ex Ponto C.N.F.P.A. Publishing House, Bucharest.

Bourdon PC, Cardinale M, Murray A, Gastin P, Kellmann M, Varley MC, Gabbett TJ, Coutts AJ, Burgess DJ, Gregson W, Cable NT. 2017. Monitoring athlete training loads. Consensus statement. International Journal of Sports Physiology and Performance 12(Suppl. 2):S2161-S2170 DOI:10.1123/IJSPP.2017-0208.

Blásquez JCC, Font GR, Ortís LC. 2009. Heart-rate variability and precompetitive anxiety in swimmers. Psicothema 21(4): 531-536.

Britton D, Kavanagh E, Polman R. 2017. The perceived stress reactivity scale for adolescent athletes. Personality and Individual Differences 116: 301-308

DOI:10.1016/j.paid.2017.05.008.

Caracsso L, Villaverde C, Oltrans CM. 2007. Endorphin responses to stress induced by competitive swimming event. Journal of Sports Medicine and Physical Fitness 47(2):239245.

Cohen LH, Towbes LC, Flocco R. 1988. Effects of induced mood on self-reported life events and perceived and received social support. Journal of personality and social psychology 55(4): 669-674 DOI:10.1037/0022-3514.55.4.669.

Cohen S, Williamson G. 1988. Perceived stress in a probability sample of the United States. In S. Spacapan, \& S. Oskamp (Eds.), The social psychology of health: Claremont symposium on applied social psychology (p.31-67). Newbury Park, CA: Sage.

Crăciun M. 2012. Psihologia sportului pentru antrenori [Sports Psychology for Coaches]. Risoprint Publishing House, Bucharest, 96-97.

Crewther BT, Al-Dujaili E, Smail NF, Anastasova S, Kilduf LP, Cook CJ. 2013. Monitoring salivary testosterone and cortisol concentrations across an international sports competition: Data comparison using two enzyme immunoassays and two sample preparations. Clinical Biochemistry 46(4-5):354-358 DOI: 10.1016/j.clinbiochem.2012.11.019.

de Winter JCF, Gosling SD, Potter J. 2016. Comparing the Pearson and Spearman correlation coefficients across distributions and sample sizes: A tutorial using simulations and empirical data. Psychological Methods 21(3), 273-290 DOI:10.1037/met0000079.

Dias P, Marques M, Marinho D. 2012. Performance evaluation in young swimmers during 28 weeks of training. Journal of Physical Education and Sport 12:30-38 DOI:10.7752/jpes.2012.01006.

Dimitriou L, Sharp NCC, Doherty M. 2002. Circadian effects on the acute responses of salivary cortisol and IgA in well trained swimmers. British Journal of Sports Medicine 36(4): 260264 DOI: $10.1136 /$ bjsm.36.4.260.

Peer) reviewing PDF | (2021:01:57290:3:0:NEW 23 May 2021) 
673 Dormehl, S.J.; Robertson, S.J.; Williams, C.A. 2016. Modelling the Progression of Male

674

675

676

677

678

679

680

681

682

683

684

685

686

687

688

689

690

691

692

693

694

695

696

697

698

699

700

701

702

703

704

705

706

707

708

709

710

711

Swimmers' Performances through Adolescence. Sports 4(1), 2

DOI: $10.3390 /$ sports 4010002 .

Drăgan I. 2002. Medicina sportivă [Sports Medicine]. Bucharest: Medical Publishing House. Dragnea A, Teodorescu-Mate S. 2002. Teoria Sportului [Sports Theory]. Bucharest: FEST.

Ferreira S, Carvalho D, Monteiro AS, Abraldes JAA, Vilas-Boas JP, Toubekis A, Fernandes R. 2019. Physiological and Biomechanical Evaluation of a Training Macrocycle in Children Swimmers. Sports 7(3), 57, 1-9 DOI: 10.3390/sports7030057.

Franken M, Mazzola PN, Dutra-Filho CS, de Souza Castro FA. 2018. Acute biochemical and physiological responses to swimming training series performed at intensities based on the 400-m front crawl speed. Sport Sciences for Health 14:633-638 doi:10.1007/s11332-0180472-z.

Fritz CO, Moris PF, Richler JJ. 2012. Effect Size Estimates: Current Use, Calculations, and Interpretation. Journal of Experimental Psychology: General 141(1):2-18 DOI:10.1037/a0024338.

Godoy-Izquierdo D, Sola HC, Godoy GJF. 2011. Assessing Coping with Stress Self-Efficacy: English Validation of the CSSES. Health Outcomes Research in Medicine 2(2):e105-e118 DOI:10.1016/j.ehrm.2011.06.001.

Grosu VT, Toader F, Ciufudean E, Grosu EF. 2015. Attention and emotional distress in junior athletes practicing judo and alpine skiing. Palestrica of the third millennium-Civilization and Sport 16(4):338-341.

Hogue CM, Fry MD, Fry AC. 2017. The differential impact of motivational climate on adolescents' psychological and physiological stress responses. Psychology of Sport and Exercise 30:118-127 DOI:10.1016/j.psychsport.2017.02.004.

Iurea C, Safta CG. 2018. The Impact of Academic Stress on Students' Performance. Chapter 8 In: Violence Prevention and Safety Promotion in Higher Education Settings. IGI Global Publisher of Timely Knowledge:128-153DOI: 10.4018/978-1-5225-2960-6.ch008.

Jiménez M, Aguilar R, Alvero-Cruz JR. 2012. Effects of victory and defeat on testosterone and cortisol response to competition: evidence for same response patterns in men and women. Psychoneuroendocrinology 37(9):1577-1581 DOI:10.1016/j.psyneuen.2012.02.011.

Jiménez M, Fernández-Navas M, Alvero-Cruz JR, García-Romero J, García-Coll V, Rivilla I, Clemente-Suárez VJ. 2019. Differences in psychoneuroendocrine stress responses of highlevel swimmers depending on autocratic and democratic coaching style. International journal of environmental research and public health 16(24),5089 DOI:10.3390/ijerph16245089.

Jones B, Parry D, Cooper CE.2018. Underwater near-infrared spectroscopy can measure training adaptations in adolescent swimmers. PeerJ6:e4393; DOI 10.7717/peerj.4393.

Judge, LW, Urbina, LJ, Hoover, DL, Craig, BW, Judge, LM, Leitzelar, BM, Pearson, DR, Holtzclaw, KA, and Bellar, DM. 2016. The impact of competitive trait anxiety on

Peer) reviewing PDF | (2021:01:57290:3:0:NEW 23 May 2021) 
712

713

714

715

716

717

718

719

720

721

722

723

724

725

726

727

728

729

730

731

732

733

734

735

736

737

738

739

740

741

742

743

744

745

746

747

748

749

collegiate powerlifting performance. Journal of Strength and Conditioning Research 30(9): 2399-2405.

Kanaley JA, Weltman JY, Karen S. Piperarthur W, Hartman ML. 2001.Cortisol and Growth Hormone Responses to Exercise at Different Times of Day. The Journal of Clinical Endocrinology \& Metabolism 86(6):2881-2889 DOI: 10.1210/jcem.86.6.7566.

Kellmann M, Beckmann J. (eds). 2018. Sport, Recovery, and Performance: Interdisciplinary Insights. New York, NY: Routledge.

Kellmann M, Bertollo M, Bosquet L, Brink MS, Coutts A, Duffield R, Erlacher D, Halson SL, Hecksteden A, Heidari J, Kallus KW, Meeusen R, Mujika I, Robazza C, Skorski S, Venter R, Beckmann J. 2018. Recovery and performance in sport: consensus statement. International Journal of Sports Physiology and Performance 13:240-245 DOI:10.1123/ijspp.2017-0759.

Kim S, Park S, Love A, Pang TC. 2021. Coaching style, sport enjoyment, and intent to continue participation among artistic swimmers. International Journal of Sports Science \& Coaching DOI:10.1177/1747954120984054

Kirschbaum C, Hellhammer DH. 1989. Salivary cortisol in psychobiological research: an overview. Neuropsychobiology 22(3):150-169 DOI:10.1159/000118611.

Machado M, Júnior O, Marques A, Colantonio E, Cyrino E, De Mello, M. 2011. Effect of 12 weeks of training on critical velocity and maximal lactate steady state in swimmers. European Journal of Sport Science 11:165-170 DOI:10.1080/17461391.2010.499973.

Maglischo EW. 1993. Swimming even faster. McGraw-Hill Humanities, Social Sciences \& World Languages.

Matthews G, Deary IJ, Whiteman MC. 2005. Psihologia Personalităţii [Personality Psychology]. Iaşi: Polirom Publishing House.

Mellalieu SD, Neil R, Hanton S, Fletcher D. 2009. Competition stress in sport performers: Stressors experienced in the competition environment. Journal of sports sciences27(7):729-744 DOI:10.1080/02640410902889834.

Meyer MS. 1988. Ethical principles of psychologists and religious diversity. Professional Psychology: Research and Practice 19(5):486-488 DOI:10.1037/0735-7028.19.5.486

Mihăilescu L, Dubiţ NS. 2015. Practical Experiences in Using the Simulation Method of Learning the Sportive Technique in Swimming. Procedia - Social and Behavioral Sciences 180:1276-1282 DOI:10.1016/j.sbspro.2015.02.264.

Mihăilescu L. 2018. Dirijarea efortului în antrenament și competiție [Guiding the effort in training and competition]. Course support, "Performance in sport" master's degree. University of Pitești

Morais JE, Garrido N, Marques M, Silva A, Marinho D, Barbosa T. 2013. The influence of anthropometric, kinematic and energetic variables and gender on swimming performance in youth athletes. Journal of Human Kinetics 39:203-211 DOI:10.2478/hukin-2013-0083.

Peer) reviewing PDF | (2021:01:57290:3:0:NEW 23 May 2021) 
750

751

752

753

754

755

756

757

758

759

760

761

762

763

764

765

766

767

768

769

770

771

772

773

774

775

776

777

778

779

780

781

782

783

784

785

786

787

788

Morais JE, Marques MC, Marinho DA, Silva AJ, Barbosa TM. 2014. Longitudinal modeling in sports: Young swimmers 'performance and biomechanics profile. Human Movement Science 37:111-122 DOI:10.1016/j.humov.2014.07.005.

Morais JE, Forte P, Silva A, Barbosa T, Marinho D. 2020. Data modeling for interand intraindividual stability of young swimmers 'performance: a longitudinal cluster analysis. Research Quarterly for Exercise and Sport, published online ahead of print, 1-13 DOI:10.1080/02701367.2019.1708235.

Moreira M, Morais J, Marinho D, Silva A, Barbosa T, Costa M. 2014. Growth influences biomechanical profile of talented swimmers during the summer break. Sports Biomechanics 13:62-74 DOI:10.1080/14763141.2013.865139.

Moser C, Sousa CV, Olher RR, Nikolaidis PT, Knechtle, B. 2020. Pacing in World-Class Age Group Swimmers in 100 and 200 m Freestyle, Backstroke, Breaststroke, and Butterfly. Int. J. Environ. Res. Public Health 2020, 17(11), 3875. DOI: 10.3390/ijerph17113875.

Mrakic-Sposta S, Gussoni M, Porcelli S, Pugliese L, Pavei G, Bellistri G, Montorsi M, Tacchini P, Vezzoli A. 2015. Training Effects on ROS Production Determined by Electron Paramagnetic Resonance in Master Swimmers. Oxidative Medicine and Cellular Longevity2015. DOI: 10.1155/2015/804794.

Nicolas M, Vacher P, Martinent G, Mourot L. 2019. Monitoring stress and recovery states: Structural and external stages of the short version of the RESTQ sport in elite swimmers before championships. Journal of Sport and Health Science 8(1): 77-88

DOI:10.1016/j.jshs.2016.03.007

Niemana DC, Wentz, LM. 2019. The compelling link between physical activity and the body's defense system. Journal of Sport and Health Science 8(3):201-217

DOI:10.1016/j.jshs.2018.09.009

Nikitakis IS, Paradisis GP, Bogdanis GC, Toubekis AG. 2019. Physiological Responses of Continuous and Intermittent Swimming at Critical Speed and Maximum Lactate Steady State in Children and Adolescent Swimmers. Sports 7(1), 25 DOI:10.3390/sports7010025

Nikseresht A, Yabande AA, Rahmanian K. 2017. Pre-Competition Anxiety Score among Elite Boy Swimmers in Iran. World family medicine / Middle East journal of family medicine 15(6):65-70DOI:10.5742/MEWFM.2017.92986

Nunes RSM, Hanna Souza Messias HS, Vieir E. 2020. Individualized program with periodization with low intensity and biomechanics improves swimming triathlete technique and performance. Sport Performance \& Science Reports 94 (https://sportperfsci.com/individualized-program-with-periodization-with-low-intensityand-biomechanics-improves-swimming-triathlete-technique-and-performance/ - accessed 26.02.2021).

Papadopoulos E, Muir C, Russell C, Timmons, BW, Falk, B, Klentrou, P. 2014. Markers of biological stress and mucosal immunity during a week leading to competition in adolescent swimmers. Journal of immunology research 2014, 1-7 DOI: 10.1155/2014/234565.

Peer) reviewing PDF | (2021:01:57290:3:0:NEW 23 May 2021) 
789

790

791

792

793

794

795

796

797

798

799

800

801

802

803

804

805

806

807

808

809

810

811

812

813

814

815

816

817

818

819

820

821

822

823

824

825

826

827

Parnabas V, Parnabas J, Parnabas AM. 2015. The Level of Cognitive Anxiety and Sport Performance among Swimmers. The International Journal of Indian Psychology 2: 48-55. Platonov VN. 2015. System of sportsmen's training in Olympic sports. Kiev, Olympic Literature. Polman R, Rowcliffe N, Borkoles E, Levy A. (2007). Precompetitive State Anxiety, Objective and Subjective Performance, and Causal Attributions in Competitive Swimmers. Pediatric Exercise Science 19, 39-50 DOI:10.1123/pes.19.1.39

Rodríguez-Zamora L, Iglesias X, Barrero A, Chaverri D, Erola P, Rodríguez FA. 2012. Physiological responses in relation to performance during competition in elite synchronized swimmers. PLoS One 7(11): e49098 DOI:10.1371/journal.pone.0049098.

Salgau S, Iorgulescu G, Creteanu, MM. 2008. Metodologie de antrenament în nataţie pe simulatorul de conditii "Ergosim" [Training methodology on the "Ergosim" condition simulator in swimming]. Gymnasium 9(12):117-130.

Sargent C, Lastella M, Halson SL, Roach GD. 2014. The impact of training schedules on the sleep and fatigue of elite athletes. Chronobiology International 31(10):1160-1168 DOI:10.3109/07420528.2014.957306.

Șalgău S. 2005. Bazele reglării efortului la înotătorii de mare performanță [Basics of effort regulation in high performance swimmers], Iaşi: Tehnopress Publishing House.

Şalgău S. 2017. The Role of Biochemical Tests and of New Methods in Training Monitoring at Performance Swimmers. Gymnasium - Scientific Journal of Education, Sports and Health 18(2):55-72 DOI: 10.29081/gsjesh.2017.18.2.04.

Šarotar-Žižek S, Treven S, Čančer, V. 2013. Individual and organizational approaches to overcoming stress. Scientific Annals of the "AlexandruIoanCuza" University of Iaşi Economic Sciences 60(2):104-121DOI 10.2478/aicue-2013-0020.

Smith DJ, Norris SR, Hogg JM. 2002. Performance evaluation of swimmers. Sports medicine 32(9):539-554 DOI:10.2165/00007256-200232090-00001.

Smith RE, Smoll FL, Schutz RW. 2007. Measurement and correlates of sport-specific cognitive and somatic trait anxiety: The sport anxiety scale. Anxiety research 2(4):263-280 DOI:10.1080/08917779008248733.

Soria M, González-Haro, C, Ansón M, López-Colón, JL, Escanero, JF. 2015.Plasma levels of trace elements and exercise induced stress hormones in well-trained athletes, Journal of Trace Elements in Medicine and Biology 31:113-119 DOI:10.1016/j.jtemb.2015.04.004.

Souglis A, Travlos KA. 2015. The influence of competitive activity on selected biochemical and haematological parameters of amateur soccer athletes. Journal of Physical Education and Sport 15(1):24-31 DOI:10.7752/jpes.2015.01005.

Soultanakis H, Platanou T. 2008. Effect of dietary carbohydrate content on blood glucose levels of swimmers during training. Journal of Sports Medicine and Physical Fitness 48(3):335340.

Sperlich B, Zinner C, Heilemann I, Kjendlie PL, Holmberg HC, Mester J. 2010. High-intensity interval training improves VO2peak, maximal lactate accumulation, time trial and

Peer) reviewing PDF | (2021:01:57290:3:0:NEW 23 May 2021) 
828

829

830

831

832

833

834

835

836

837

838

839

840

841

842

843

844

845

846

847

848

849

850

851

852

853

854

855

856

857

858 competition performance in 9-11-year-old swimmers. European Journal of Applied Physiology110:1029-1036 DOI 10.1007/s00421-010-1586-4.

Tucher G, Castro FAS, Garrido N, Fernandes R. 2019. Monitoring changes over a training macrocycle in regional age-group swimmers. Journal of human kinetics 69:213-223 doi:10.2478/hukin-2019-0014.

Ulmeanu FC. 1967. Estandarización de las pruebas de aptitudfísicaen los paises de Europa oriental. ApuntsMedicina de l" Esport (Castellano) 4(16):227-232.

Vovkanych L, and Penchuk A. 2015. The Interrelationship between Performance Parameters and Variables of Respiratory Function of Orienteers. Journal of Physical Education and Sport 15(3):446 - 451DOI:10.7752/jpes.2015.03067.

Ware LB, Matthay MA. 2000. The acute respiratory distress syndrome. New England Journal of Medicine342(18): 1334-1349DOI: 10.1056/NEJM200005043421806.

Whdan N. 2014. Effects of relaxation training on muscle tension and the performance level of 50m front crawl swimming. Ovidius University Annals, Series Physical Education and Sport/Science, Movement and Health14(1):143-148.

Woodman T, Hardy L. 2003. The relative impact of cognitive anxiety and self-confidence upon sport performance: a meta-analysis. Journal of Sports Sciences 21(6):443-457

DOI:10.1080/0264041031000101809.

World Health Organization. 2000. Air quality guidelines for Europe, 2nd edition. Copenhagen: WHO Regional Office for Europe Available at https://apps.who.int/iris/handle/10665/107335.

Yoshioka K. 2002. KyPlot-A User-oriented Tool for Statistical Data Analysis and Visualization. Computational Statistics17(3):425-437 DOI:10.1007/s001800200117.

Zacca R, Azevedo R, Chainok P, Vilas-Boas JP, Castro FA, Pyne D, Fernandes R. 2018.

Monitoring age-group swimmers over a training macrocycle: energetics, technique, and anthropometrics. Journal of Strength and Conditioning Research 34(3):818-827 doi:10.1519/JSC.0000000000002762.

Zacca R, Azevedo R, Silveira RP, Vilas-Boas JP, Pyne DB, Castro FAS, Fernandes RJ. 2019. Comparison of incremental intermittent and time trial testing in age-group swimmers. Journal of Strength and Conditioning Research 33(3):801-810 DOI:10.1519/JSC.0000000000002087. 
Figure 1

Volume of the means of training in the young swimmers at the beginning and the end of the research according to the specialized styles

T.E. - technique exercises; WL - workouts for legs; $R 1$ zone - basic endurance; $R 2$ zones threshold resistance; S1 - lactate tolerance; S2 zone - lactate production

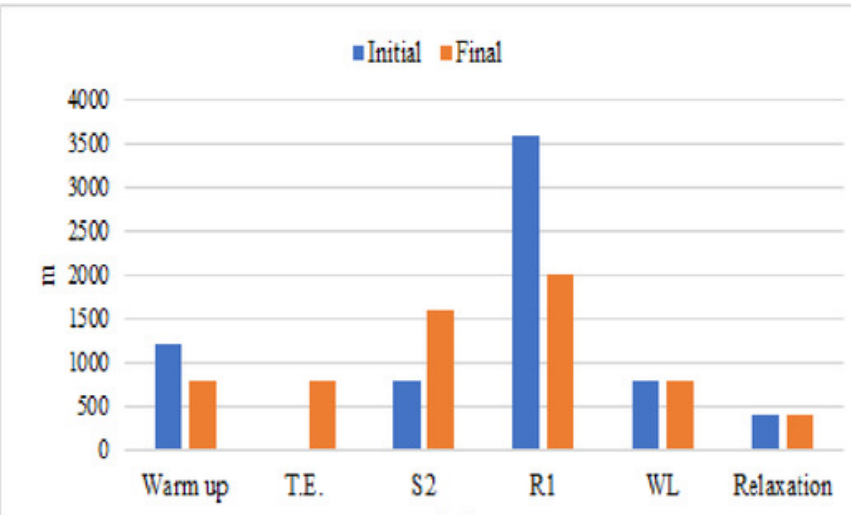

a) Athlete - A1 (backstroke)
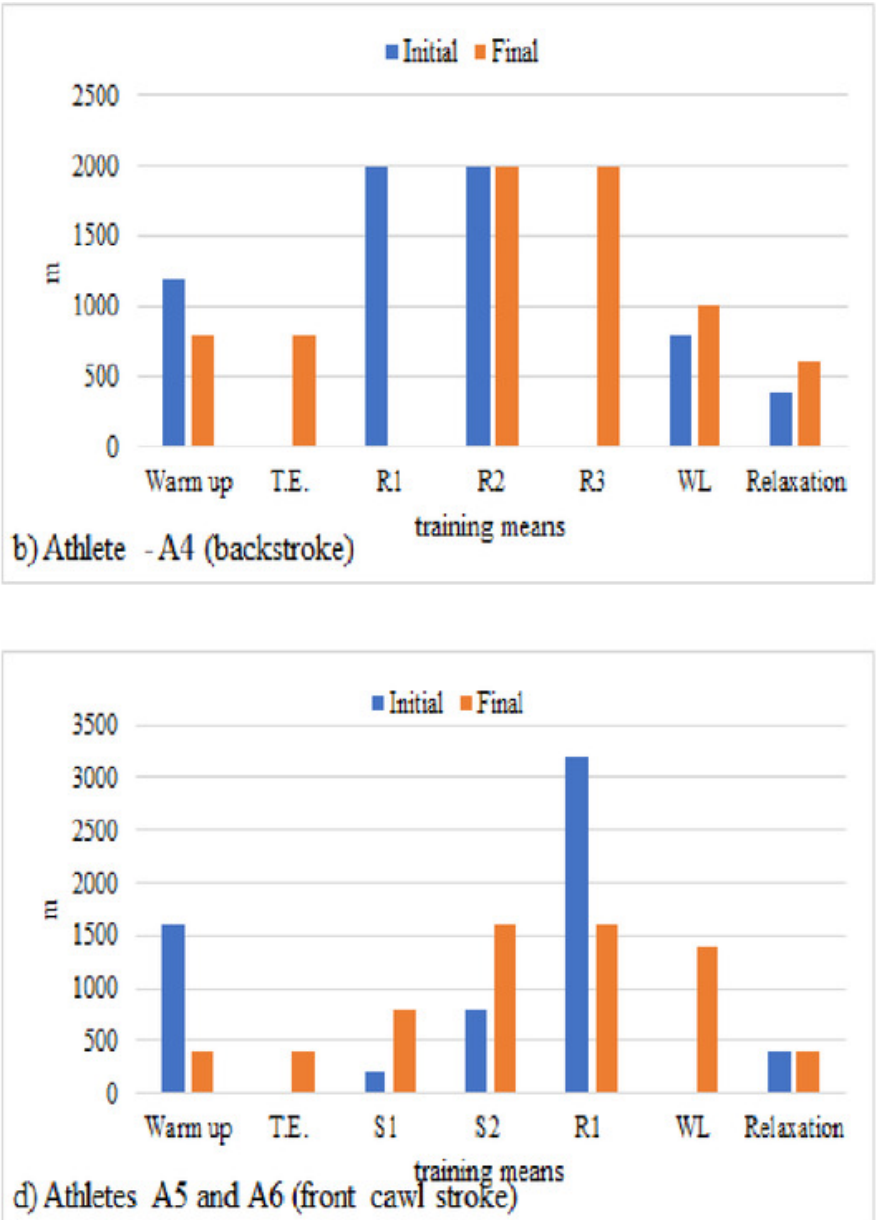


\section{Table $\mathbf{1}$ (on next page)}

Graph of mental, motor and biochemical indicators monitoring in macrocycle 2, 2015-2016 plan

$\psi$ - psychological testing; B - biochemical testing; B: MT\&C - biochemical testing in training and competition; General - stage I (E1); Specific - stage II (E2); Pre-Cp. - Pre-competitive stage III (E3); Cp. - Competitive - stage IV (E4); T1- beginning of the baseline research; T2 testing in end of general stage; T3 - testing end of specific stage; T4 - testing in competitive stage; MT - motor test; Jr. - Junior athlete (A1); Cd. - Cadet athlete (A4); B\&MT1 - testing of La and Glu in motor test 8x100 m; B\&MT2 - testing of La (lactate) and Glu (glucose) in motor test $2 \times 50 \mathrm{~m}$ 


\begin{tabular}{|c|c|c|c|c|c|c|c|c|c|c|c|c|c|c|c|c|}
\hline Month & \multicolumn{4}{|c|}{ Jan. } & \multicolumn{4}{|c|}{ Feb. } & \multicolumn{4}{|c|}{ March } & \multicolumn{3}{|c|}{ April } & \multirow[b]{2}{*}{ Total } \\
\hline Indicators & Week & \begin{tabular}{|l|}
08 \\
15
\end{tabular} & $\begin{array}{l}18 \\
24\end{array}$ & $\begin{array}{l}25 \\
31\end{array}$ & $\begin{array}{l}01 \\
07\end{array}$ & \begin{tabular}{|l|}
08 \\
14
\end{tabular} & $\begin{array}{l}15 \\
21\end{array}$ & $\begin{array}{l}22 \\
28\end{array}$ & $\begin{array}{l}29 \\
06\end{array}$ & $\begin{array}{l}07 \\
13\end{array}$ & $\begin{array}{l}14 \\
20\end{array}$ & $\begin{array}{l}21 \\
27\end{array}$ & $\begin{array}{l}28 \\
03\end{array}$ & $\begin{array}{l}04 \\
10\end{array}$ & $\begin{array}{l}11 \\
17\end{array}$ & \\
\hline Stages & \multirow{3}{*}{ Jr. } & & \multicolumn{4}{|c|}{ General } & \multicolumn{3}{|c|}{ Specific } & \multicolumn{2}{|c|}{ Pre-Cp. } & $\mathrm{Cp}$. & \multicolumn{2}{|c|}{-} & - & \\
\hline$\Psi$ & & $\Psi_{\mathrm{T} 1}$ & \multicolumn{4}{|c|}{$\Psi_{\mathrm{T} 2}$} & \multicolumn{3}{|c|}{$\Psi_{\mathrm{T} 3}$} & & & $\overline{\Psi_{\mathrm{T} 4}}$ & \multicolumn{2}{|c|}{ - } & - & \\
\hline B: MT\&C & & $\mathrm{B}_{\mathrm{T} 1}$ & \multirow{2}{*}{\multicolumn{5}{|c|}{$\begin{array}{l}\text { B\&MT1 } \\
\text { General }\end{array}$}} & & MT1 & B\& & MT2 & $\mathrm{B} \& \mathrm{C}$ & \multicolumn{2}{|c|}{-} & - & \\
\hline Stages & \multirow{3}{*}{$\mathrm{Cd}$. } & & & & & & & \multicolumn{5}{|c|}{ Specific } & \multicolumn{2}{|c|}{ Pre-Cp. } & Cp. & \\
\hline$\Psi$ & & $\Psi_{\mathrm{T} 1}$ & \multicolumn{5}{|c|}{$\Psi_{\mathrm{T} 2}$} & \multicolumn{5}{|c|}{$\Psi_{\mathrm{T} 3}$} & & & $\overline{\Psi_{\mathrm{T} 4}}$ & \\
\hline B: MT\&C & & $\mathrm{B}_{\mathrm{T1}}$ & \multicolumn{5}{|c|}{ B\&MT1 } & \multicolumn{4}{|c|}{ B\&MT1 } & & \multicolumn{2}{|c|}{ B\&MT2 } & $\mathrm{B} \& \mathrm{C}$ & \\
\hline \multirow{2}{*}{$\begin{array}{l}\text { Days of } \\
\text { training }\end{array}$} & Jr. & & 6 & 6 & 6 & 6 & 6 & 6 & 6 & 6 & 7 & 3 & - & - & - & 58 \\
\hline & Cd. & & 6 & 6 & 6 & 6 & 6 & 6 & 6 & 6 & 6 & $\bar{~} 6$ & 6 & 6 & 7 & 79 \\
\hline \multirow[t]{2}{*}{ Days of rest } & Jr. & & 1 & 1 & 1. & 1 & 1 & 1 & 1 & 1 & 0 & 0 & - & - & - & 8 \\
\hline & $\mathrm{Cd}$. & & 1 & 1 & 1 & 1 & 1 & 1 & 1 & 0 & 1 & 1 & 1 & 1 & 0 & 11 \\
\hline \multirow{2}{*}{$\begin{array}{l}\text { In water } \\
\text { training }\end{array}$} & Jr. & & 8 & 9 & 9 & 9 & 9 & 9 & 9 & 9 & 9 & 4 & - & - & - & 84 \\
\hline & Cd. & & 8 & 9 & 9 & 9 & 9 & 9 & 9 & 8 & 8 & 9 & 9 & 9 & 8 & 113 \\
\hline \multirow{2}{*}{$\begin{array}{l}\text { Off water } \\
\text { training }\end{array}$} & Jr. & & 5 & 5 & 4 & 4 & 4 & 4 & 3 & 2 & 0 & 0 & - & - & - & 31 \\
\hline & $\mathrm{Cd}$. & & 5 & 3 & 3 & 3 & 2 & 2 & 3 & 2 & 2 & 2 & 2 & 2 & 2 & 33 \\
\hline Total training & Jr. & & 13 & 14 & 12 & 12 & 13 & 13 & 12 & 11 & 9 & 4 & - & - & - & 113 \\
\hline & $\mathrm{Cd}$. & & 13 & 12 & 12 & 12 & 11 & 11 & 12 & 10 & 10 & 11 & 11 & 11 & 10 & 146 \\
\hline Hours in & Jr. & & 16 & 18 & 22 & 22 & 20 & 20 & 18 & 18 & 18 & 8 & - & - & - & 180 \\
\hline wate & Cd. & & 10 & 18 & 22 & 24 & 22 & 24 & 26 & 24 & 28 & 24 & 24 & 15 & 8 & 269 \\
\hline Hours off & Jr. & & 3 & 2.3 & 2 & 2 & 2 & 2 & 2 & 1 & 0 & 0 & - & - & - & 16.3 \\
\hline water & $\mathrm{Cd}$. & & 5 & 3 & 3 & 3 & 2 & 2 & 3 & 2 & 2 & 2 & 2 & 1 & 1 & 31 \\
\hline Total of hours & $\mathrm{Jr}$. & & 19 & 20.3 & 24 & 24 & 22 & 22 & 20 & 19 & 18 & 8 & - & - & - & 196.3 \\
\hline & $\mathrm{Cd}$. & & 15 & 21 & 25 & 27 & 24 & 26 & 29 & 26 & 30 & 26 & 26 & 16 & 9 & 300 \\
\hline Volume km & $\mathrm{Jr}$. & & 42 & 45 & 50 & 55 & 55 & 53 & 45 & 30 & 30 & 12 & - & - & - & 417 \\
\hline & $\mathrm{Cd}$. & & 40 & 45 & 45 & 50 & 45 & 50 & 55 & 50 & 60 & 250 & 44 & 34 & 12 & 580 \\
\hline & & & & & & & & & & & & & & & & \\
\hline
\end{tabular}




\section{Table 2 (on next page)}

Psychological particularities of stress perception of the young swimmers under the influence of stimuli from training and competition $(n=6)$

T1- beginning of the baseline research; T2 - testing in end of general stage; T3 - testing end of specific stage; T4 - testing in competitive stage ; $A$ - cognitive; $B$ - somatic; $C$ - selfconfidence; Cohen's d effect size (Small 0.2; Medium 0.5; Large 0.8; Very large 1.3); PS probability of superiority; Z - Wilcoxon Signed Rank Test for Paired Data; X2 - Friedman Test With Replication; T1\# - comparison with T4; T4\# - comparison with A, B, C; * - $p<0.05$; ** $p<0.01$ 


\begin{tabular}{|c|c|c|c|c|c|c|c|c|c|}
\hline \multicolumn{3}{|c|}{ Psychological indicators } & $\begin{array}{l}\text { Median; } \\
\quad \pm \text { SD; }\end{array}$ & Range & $\begin{array}{c}\text { Cronbach`s } \\
\text { Alpha }\end{array}$ & Cohen's d & $\begin{array}{l}\text { PS } \\
(\%)\end{array}$ & Z; p-value & $\begin{array}{c}X^{2} ; \\
p-v a l u e\end{array}$ \\
\hline \multirow[t]{4}{*}{ CWT (points) } & \multicolumn{2}{|c|}{ T1\# } & $27.5 \pm 1.58$ & 13 & .545 & 1.66 & 87 & $2.032 ; .057$ & \multirow{4}{*}{$\begin{array}{l}10.12 ; \\
.018^{*}\end{array}$} \\
\hline & \multicolumn{2}{|l|}{$\mathrm{T} 2$} & $29.5 \pm 1.64$ & 12 & .602 & .47 & 61 & $2.232 ; .033 *$ & \\
\hline & \multicolumn{2}{|l|}{ T3 } & $32.5 \pm 1.35$ & 8 & .588 & .66 & 66 & $0.843 ; .461$ & \\
\hline & \multicolumn{2}{|l|}{$\mathrm{T} 4$} & $36.0 \pm 2.11$ & 12 & .423 & .63 & 66 & $1.632 ; .208$ & \\
\hline \multirow[t]{4}{*}{ CPST (points) } & \multicolumn{2}{|c|}{ T1\# } & $16.0 \pm 2.66$ & 7 & .273 & 2.26 & 94 & $1.992 ; .059$ & \multirow{4}{*}{$\begin{array}{l}9.54 ; \\
.023 *\end{array}$} \\
\hline & \multicolumn{2}{|l|}{$\mathrm{T} 2$} & $21.5 \pm 2.32$ & 6 & .097 & 1.44 & 84 & $2.032 ; .057$ & \\
\hline & \multicolumn{2}{|l|}{ T3 } & $22.0 \pm 1.64$ & 4 & -2.798 & .57 & 64 & $1.479 ; .169$ & \\
\hline & \multicolumn{2}{|l|}{$\mathrm{T} 4$} & $23.5 \pm 1.75$ & 5 & -1.401 & .51 & 64 & $0.812 ; .498$ & \\
\hline SCAT (points) & \multicolumn{2}{|c|}{ T4\# } & $21.5 \pm 5.91$ & 15 & .878 & - & - & - & \multirow{4}{*}{$\begin{array}{l}13.17 \\
.004 * *\end{array}$} \\
\hline \multirow[t]{3}{*}{ CT (points) } & \multirow{3}{*}{$\mathrm{T} 4$} & $\mathrm{~A}$ & $8.5 \pm 2.66$ & 8 & .845 & - & - & $2.213 ; .035^{*}$ & \\
\hline & & $\mathrm{B}$ & $6.5 \pm 1.63$ & 4 & -.113 & - & - & $2.207 ; .035^{*}$ & \\
\hline & & $\mathrm{C}$ & $8.5 \pm 1.79$ & 5 & .750 & - & - & $2.201 ; .036^{*}$ & \\
\hline
\end{tabular}




\section{Table 3 (on next page)}

Results of blood glucose and lactate concentration in pre- and post-effort motor tests in different stages of training $(n=6)$

stage I (E1), general; stage II (E2), specific; stage III (E3), pre-competitive; SD - standard deviation; Cohen's d effect size; (Small 0.2; Medium 0.5; Large 0.8; Very large 1.3); PS probability of superiority; Cohen's d\# - comparison E1 - E2, E2 - E3 and E1 -E3; $X^{2}$ Friedman Test with Replication; $* p<0.05 ; * * p<0.01$ 
1

\begin{tabular}{|c|c|c|c|c|c|c|c|c|c|}
\hline \multirow[t]{2}{*}{ Stage } & \multirow[b]{2}{*}{$\begin{array}{c}\text { Motor } \\
\text { Test }\end{array}$} & \multirow[t]{2}{*}{ Statist. Ind. } & \multirow{2}{*}{$\begin{array}{c}\text { Mean } \\
\text { times } \\
(\mathrm{sec})\end{array}$} & \multicolumn{3}{|c|}{ Blood lactat $\left(\mathrm{mmol} \cdot \mathrm{L}^{-1}\right)$} & \multicolumn{3}{|c|}{ Blood glucose $\left(\mathrm{mmol} \cdot \mathrm{L}^{-1}\right)$} \\
\hline & & & & $\begin{array}{l}\text { pre- } \\
\text { effort }\end{array}$ & $\begin{array}{c}\text { post- } \\
\text { effort } 5 \\
\text { min }\end{array}$ & $\begin{array}{l}\text { post- } \\
\text { effort } \\
15 \mathrm{~min}\end{array}$ & $\begin{array}{l}\text { pre- } \\
\text { effort }\end{array}$ & $\begin{array}{c}\text { post- } \\
\text { effort } 5 \\
\text { min }\end{array}$ & $\begin{array}{l}\text { post- } \\
\text { effort } 15 \\
\text { min }\end{array}$ \\
\hline \multirow[t]{6}{*}{ E1 } & \multirow[t]{6}{*}{$8 \times 100 \mathrm{~m}$} & $\begin{array}{l}\text { Median; } \\
\pm \mathrm{SD}\end{array}$ & $\begin{array}{l}80.4 ; \\
\pm 4.07\end{array}$ & $\begin{array}{l}1.24 \\
\pm 0.59\end{array}$ & $\begin{array}{l}6.25 \\
\pm 2.85\end{array}$ & $\begin{array}{l}5.35 \\
\pm 2.04\end{array}$ & $\begin{array}{l}103.5 \\
\pm 9.33\end{array}$ & $\begin{array}{l}118.5 ; \\
\pm 23.44\end{array}$ & $\begin{array}{c}105 ; \\
\pm 16.41\end{array}$ \\
\hline & & Range & 11.22 & 0.17 & 8.2 & 5.3 & 26 & 58 & 42 \\
\hline & & Cohen's d\# & 2.09 & 0.08 & 12.44 & 0.01 & 0.84 & 0.05 & 0.09 \\
\hline & & PS (\%) & 56 & 52 & 100 & 50 & 72 & 51 & 52 \\
\hline & & $\mathrm{X}^{2}$ & - & \multicolumn{3}{|c|}{12.00} & \multicolumn{3}{|c|}{4.00} \\
\hline & & $p$-value & - & \multicolumn{3}{|c|}{$.002 * *$} & \multicolumn{3}{|c|}{.135} \\
\hline \multirow[t]{6}{*}{ E2 } & \multirow[t]{6}{*}{$8 \times 100 \mathrm{~m}$} & $\begin{array}{l}\text { Median; } \\
\pm \mathrm{SD}\end{array}$ & $\begin{array}{l}79.01 ; \\
\pm 3.66\end{array}$ & $\begin{array}{c}1.7 ; \\
\pm 0.74\end{array}$ & $\begin{array}{l}10.7 \\
\pm 2.29\end{array}$ & $\begin{array}{l}8.25 \\
\pm 1.91\end{array}$ & $\begin{array}{c}99 ; \\
\pm 14.56\end{array}$ & $\begin{array}{l}143.5 \\
\pm 37.02\end{array}$ & $\begin{array}{c}117 \\
\pm 28.97\end{array}$ \\
\hline & & Range & 10.2 & 1.8 & 6.4 & 4.7 & 38 & 101 & 71 \\
\hline & & Cohen's d & 0.31 & 0.05 & 1.33 & 1.29 & 0.21 & 0.87 & 0.69 \\
\hline & & PS (\%) & 58 & 51 & 82 & 81 & 56 & 72 & 68 \\
\hline & & $\mathrm{X}^{2}$ & - & \multicolumn{3}{|c|}{12.00} & \multicolumn{3}{|c|}{6.33} \\
\hline & & $\mathrm{p}$-value & - & \multicolumn{3}{|c|}{$.002 * *$} & \multicolumn{3}{|c|}{$.042 *$} \\
\hline \multirow[t]{6}{*}{ E3 } & \multirow[t]{6}{*}{$2 \times 50 \mathrm{~m}$} & $\begin{array}{l}\text { Median; } \\
\quad \pm \text { SD }\end{array}$ & $\begin{array}{l}71.9 \\
5.84\end{array}$ & $\begin{array}{l}1.9 \\
0.44\end{array}$ & $\begin{array}{l}9.1 ; \\
1.44\end{array}$ & $\begin{array}{l}6.7 \\
0.83\end{array}$ & $\begin{array}{c}97 ; \\
14.2\end{array}$ & $\begin{array}{c}122 ; \\
18.15\end{array}$ & $\begin{array}{l}98.5 \\
16.36\end{array}$ \\
\hline & & Range & 17.3 & 1.3 & 4 & 2 & 40 & 53 & 41 \\
\hline & & Cohen's d & 1.99 & 0.11 & 0.65 & 0.58 & 0.40 & 0.52 & 0.44 \\
\hline & & PS (\%) & 91 & 53 & 66 & 64 & 61 & 64 & 62 \\
\hline & & $\mathrm{X}^{2}$ & - & \multicolumn{3}{|c|}{12.00} & \multicolumn{3}{|c|}{7.00} \\
\hline & & $p$-value & - & \multicolumn{3}{|c|}{$.002 * *$} & \multicolumn{3}{|c|}{$.03 *$} \\
\hline
\end{tabular}

2 


\section{Table 4 (on next page)}

Results of the modification of the metabolic and hormonal parameters in the $100 \mathrm{~m}$ specialized event in pre - and post-effort $(n=6)$

$S D$ - standard deviation; Cohen's d effect size; (Small 0.2; Medium 0.5; Large 0.8; Very large 1.3); PS - probability of superiority; Cohen's d\# - comparison basal stage with pre-effort and post-effort; $X^{2}$ - Friedman Test with Replication; $* p<0.05$; ** $p<0.01$ 


\begin{tabular}{|c|c|c|c|c|}
\hline \multirow{2}{*}{$\begin{array}{l}\text { Biochemical } \\
\text { parameters }\end{array}$} & \multirow[t]{2}{*}{ Statistics Ind. } & \multicolumn{3}{|c|}{ Measuring stages } \\
\hline & & Basal & Pre-effort & Post-effort \\
\hline \multirow[t]{5}{*}{ Lymphocytes (\%) } & Median; \pm SD & $43.65 ; \pm 7.94$ & $43.7 ; \pm 8.23$ & $52.7 ; \pm 5.96$ \\
\hline & Range & 22.9 & 22.7 & 16.3 \\
\hline & Cohen's d\# & - & .16 & .73 \\
\hline & PS (\%) & - & 54 & 69 \\
\hline & $\mathrm{X}^{2} ; \mathrm{p}$-value & \multicolumn{3}{|c|}{$1.333 ; .513$} \\
\hline \multirow{5}{*}{$\begin{array}{l}\text { Blood glucose } \\
(\mathrm{mg} / \mathrm{dl})\end{array}$} & Median; \pm SD & $86 ; \pm 9.81$ & $99.87 ; \pm 15.33$ & $122.77 ; \pm 9.56$ \\
\hline & Range & 26 & 38.67 & 20 \\
\hline & Cohen's d\# & - & .34 & 3.23 \\
\hline & PS (\%) & - & 58 & 94 \\
\hline & $\mathrm{X}^{2} ; \mathrm{p}$-value & \multicolumn{3}{|c|}{$9.000 ; .011^{*}$} \\
\hline \multirow{5}{*}{$\begin{array}{l}\text { Norepinephrine } \\
(\mathrm{mmol} / \mathrm{l})\end{array}$} & Median; \pm SD & $3.04 ; \pm 1.21$ & $1.04 ; \pm 0.75$ & $6.27 ; \pm 5.05$ \\
\hline & Range & 3.1 & 2.16 & 12.4 \\
\hline & Cohen's d\# & - & 1.23 & 4.03 \\
\hline & PS (\%) & - & 80 & 100 \\
\hline & $\mathrm{X}^{2} ; \mathrm{p}$-value & \multicolumn{3}{|c|}{$10.33 ; .005^{* *}$} \\
\hline \multirow[t]{5}{*}{ Prolactin (ng/ml) } & Median; \pm SD & $6.97 ; \pm 1.42$ & $8.93 ; \pm 4.02$ & $13.15 ; \pm 9.20$ \\
\hline & Range & 4.23 & 11.19 & 26.04 \\
\hline & Cohen's d\# & - & 1.84 & 5.87 \\
\hline & PS (\%) & - & 90 & 100 \\
\hline & $\mathrm{X}^{2} ; \mathrm{p}$-value & \multicolumn{3}{|c|}{$7.000 ; .03^{*}$} \\
\hline \multirow[t]{5}{*}{ Cortisol ( $\mu \mathrm{g} / \mathrm{dl})$} & Median; \pm SD & $12.45 ; \pm 2.4$ & $11.8 ; \pm 2.37$ & $14.25 ; \pm 3.53$ \\
\hline & Range & 6.31 & 5.88 & 9.2 \\
\hline & Cohen's d\# & - & .62 & 1.31 \\
\hline & PS (\%) & - & 66 & 82 \\
\hline & $\mathrm{X}^{2} ; \mathrm{p}$-value & \multicolumn{3}{|c|}{$8.333 ; .015^{*}$} \\
\hline
\end{tabular}




\section{Table 5 (on next page)}

Correlation coefficient for the relationship between lactate and blood glucose at each testing moment in training and the average time at MT $8 \times 100 \mathrm{~m}$ and $2 \times 50 \mathrm{~m}$, volume of effort zones, training volume, CWT și CPST ( $n=6)$

stage I (E1), general; stage II (E2), specific; stage III (E3), pre-competitive; MT - motor test; V.E.Z - volume of effort zones; T.V. - training volume; TU1 - Cohen-Williamson Test (CWT) and TU2 - Cohen Perceived Stress Test (CPST); Rho - Spearman coefficient correlation; * - $p<$ $0.05, r s=0.886$; poor correlation - 0.2; moderate correlation - 0.5 ; strong correlation -0.8 
1

\begin{tabular}{|c|c|c|c|c|c|c|c|c|c|c|c|c|c|}
\hline \multirow{2}{*}{\multicolumn{2}{|c|}{$\begin{array}{l}\text { Rho, } \\
\text { Variables }\end{array}$}} & & \multicolumn{2}{|c|}{$\begin{array}{l}\text { MT1 } \\
(\mathrm{sec})\end{array}$} & \multirow{2}{*}{$\begin{array}{l}\text { MT2 } \\
(\mathrm{sec}) \\
\text { E3 }\end{array}$} & \multicolumn{2}{|c|}{$\begin{array}{l}\text { V.E.Z. } \\
(\mathrm{km})\end{array}$} & \multicolumn{2}{|c|}{$\begin{array}{l}\text { T.V. } \\
(\mathrm{km})\end{array}$} & \multicolumn{2}{|c|}{$\begin{array}{c}\mathrm{T} \Psi 1 \\
\text { (points) }\end{array}$} & \multicolumn{2}{|c|}{$\begin{array}{c}\mathrm{T} \Psi 2 \\
\text { (points) }\end{array}$} \\
\hline & & Stage & E1 & E2 & & E1 & E3 & E1 & E3 & E1 & E2 & E1 & E2 \\
\hline \multirow{9}{*}{$\begin{array}{l}\text { Blood } \\
\text { Lactate } \\
\left(\mathrm{mmol} \cdot \mathrm{L}^{-1}\right)\end{array}$} & \multirow{3}{*}{ Pre-eff } & E1 & -.174 & & & .313 & & .224 & & -.089 & & -.058 & \\
\hline & & E2 & & -.086 & & & & & & & -.783 & & -.147 \\
\hline & & E3 & & & -.058 & & .851 & & .612 & & & & \\
\hline & \multirow{3}{*}{\begin{tabular}{|l|}
$5 \mathrm{~min}$ \\
post-eff
\end{tabular}} & E1 & -.029 & & & .559 & & .500 & & -.383 & & -.314 & \\
\hline & & E2 & & -.143 & & & & & & & $-.928^{*}$ & & -.412 \\
\hline & & E3 & & & -.086 & & .795 & & .500 & & & & \\
\hline & \multirow{3}{*}{$\begin{array}{l}15 \mathrm{~min} \\
\text { post-eff }\end{array}$} & E1 & -.086 & & & .677 & & .736 & & -.589 & & -.371 & \\
\hline & & E2 & & -.289 & & & & & & & $-.912 *$ & & -.358 \\
\hline & & E3 & & & .203 & & .806 & & .627 & & & & \\
\hline \multirow{9}{*}{$\begin{array}{l}\text { Blood } \\
\text { Glucose } \\
\left(\mathrm{mmol} \cdot \mathrm{L}^{-1}\right)\end{array}$} & \multirow[t]{3}{*}{ Pre-eff } & E1 & .657 & & & .294 & & .059 & & -.294 & & -.657 & \\
\hline & & E2 & & $.886^{*}$ & & & & & & & .145 & & -.441 \\
\hline & & E3 & & & .493 & & .045 & & -.343 & & & & \\
\hline & \multirow{3}{*}{$\begin{array}{l}5 \text { min } \\
\text { post-eff }\end{array}$} & E1 & .486 & & & .765 & & .294 & & -.412 & & $-.943^{*}$ & \\
\hline & & E2 & & .486 & & & & & & & -.638 & & -.736 \\
\hline & & E3 & & & -.2 & & .441 & & .147 & & & & \\
\hline & \multirow{3}{*}{$\begin{array}{l}15 \mathrm{~min} \\
\text { post-eff }\end{array}$} & E1 & .543 & & & .441 & & -.088 & & -.088 & & -.771 & \\
\hline & & E2 & & .6 & & & & & & & -.638 & & -.736 \\
\hline & & E3 & & & .232 & & .493 & & .313 & & & & \\
\hline
\end{tabular}

2 


\section{Table 6(on next page)}

Correlation coefficient for the relationship between psychological tests and biochemical parameters at each testing moment in the specialized event of $100 \mathrm{~m}$ with the time in competition and the biochemical parameters of the basal testing $(n=6)$

$T 1$ - beginning of the baseline research; E4 - competitive stage; $T \psi_{1}$ - Cohen-Williamson Test (CWT); T 42 - Cohen Perceived Stress Test (CPST); TW3 - Sport Competition Anxiety Test (SCAT); TW4 - Crăciun test (CT); Limf. - Lymphocytes; Glu - Blood glucose level; Norep. Norepinephrine; Prolac. - Prolactin; Cort. - Cortisol; Rho - Spearman coefficient correlation;* $p<0.05, r s=0.886$; poor correlation - 0.2; moderate correlation - 0.5; strong correlation 0.8 
1

\begin{tabular}{|c|c|c|c|c|c|c|c|c|c|c|c|c|c|}
\hline \multirow{2}{*}{\multicolumn{2}{|c|}{\begin{tabular}{|l|} 
Rho, \\
Variables
\end{tabular}}} & \multicolumn{7}{|c|}{ Stage 4 (E4) } & \multicolumn{5}{|c|}{ Basal stage (T1) } \\
\hline & & \multirow{3}{*}{\begin{tabular}{c|}
$\mathrm{T} \Psi 1$ \\
$\mathbf{1}$
\end{tabular}} & \multirow{3}{*}{\begin{tabular}{c|}
$\mathrm{T} \Psi 2$ \\
$\mathbf{2}$
\end{tabular}} & \multirow{3}{*}{\begin{tabular}{|c|}
$\mathrm{T} \Psi 3$ \\
$\mathbf{3}$ \\
\end{tabular}} & \multicolumn{3}{|c|}{ 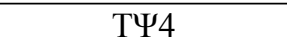 } & \multirow{3}{*}{\begin{tabular}{|l|}
$\begin{array}{l}\text { Times } \\
100 \mathrm{~m}(\mathrm{~s})\end{array}$ \\
7
\end{tabular}} & \multirow{2}{*}{$\begin{array}{c}\text { Limf. } \\
(\%)\end{array}$} & \multirow{2}{*}{$\begin{array}{c}\text { Glu } \\
(\mathrm{mg} / \mathrm{dl})\end{array}$} & \multirow{2}{*}{\begin{tabular}{|c|c} 
Norep. \\
$(\mathrm{nmol} / \mathrm{l})$
\end{tabular}} & \multirow{2}{*}{$\begin{array}{l}\text { Prolac. } \\
(\mathrm{ng} / \mathrm{ml})\end{array}$} & \multirow{2}{*}{\begin{tabular}{|c} 
Cort. \\
$(\mu \mathrm{g} / \mathrm{dl})$
\end{tabular}} \\
\hline & & & & & A & B & $\mathrm{C}$ & & & & & & \\
\hline \begin{tabular}{|l|} 
Var-s \\
\end{tabular} & E4 & & & & 4 & 5 & 6 & & 8 & 9 & 10 & 11 & 12 \\
\hline $\mathrm{T} \Psi 1$ & & & -.132 & -.319 & -.308 & \begin{tabular}{|l|}
.088 \\
\end{tabular} & -.015 & .493 & -.464 & .058 & $-.928 *$ & .174 & .377 \\
\hline $\mathrm{T} \Psi 2$ & & & & -.174 & -.294 & -.808 & -.308 & -.464 & -.116 & -.203 & .319 & -.551 & .841 \\
\hline $\mathrm{T} \Psi 3$ & & & & & $.899^{*}$ & .551 & -.174 & .086 & .371 & -.429 & .257 & .2 & -.143 \\
\hline \multirow{3}{*}{$\mathrm{T} \Psi 4$} & A & & & & & .588 & \begin{tabular}{|l|}
.088 \\
\end{tabular} & .116 & \begin{tabular}{|l|l|}
.667 \\
\end{tabular} & -.580 & .203 & -.029 & -.232 \\
\hline & $\mathrm{B}$ & & & & & & .088 & .116 & .667 & -.580 & 203 & -.029 & -.232 \\
\hline & $\mathrm{C}$ & & & & & & & .667 & .029 & .406 & -.319 & -.551 & -.232 \\
\hline \multirow[t]{2}{*}{$\begin{array}{c}\text { Limf. } \\
(\%)\end{array}$} & $\begin{array}{l}\text { Pre- } \\
\text { effort }\end{array}$ & -.348 & -.145 & .029 & .174 & .406 & -.464 & -.771 & .714 & -.6 & .543 & .257 & -371 \\
\hline & $\begin{array}{l}\text { Post- } \\
\text { effort }\end{array}$ & -.087 & -.493 & .371 & .174 & .754 & -.638 & -.257 & .029 & -.086 & .2 & $.943 *$ & -.543 \\
\hline \multirow[t]{2}{*}{$\begin{array}{c}\text { Glu } \\
(\mathrm{mg} / \mathrm{dl})\end{array}$} & $\begin{array}{l}\text { Pre- } \\
\text { effort }\end{array}$ & -.058 & -.174 & -.257 & -.551 & -.116 & -.029 & .2 & -.771 & $.886^{*}$ & -.029 & .486 & -.314 \\
\hline & $\begin{array}{l}\text { Post- } \\
\text { effort }\end{array}$ & .290 & .058 & -.086 & -.464 & -.174 & -.174 & .371 & $-.943 *$ & .714 & -.314 & .428 & .143 \\
\hline \multirow[t]{2}{*}{$\begin{array}{l}\text { Norep. } \\
(\mathrm{nmol} / \mathrm{l})\end{array}$} & $\begin{array}{l}\text { Pre- } \\
\text { effort }\end{array}$ & .209 & -.348 & -.086 & .058 & -.116 & $.928^{*}$ & $.886^{*}$ & -.257 & .543 &.- .543 & -.371 & $\mid-.143$ \\
\hline & $\begin{array}{l}\text { Post- } \\
\text { effort }\end{array}$ & -.551 & -.348 & -.143 & -.029 & .319 & -.174 & -.6 & .486 & -.086 & .6 & .314 & -.714 \\
\hline \multirow[t]{2}{*}{$\begin{array}{l}\text { Prolac. } \\
(\mathrm{ng} / \mathrm{ml})\end{array}$} & $\begin{array}{l}\text { Pre- } \\
\text { effort }\end{array}$ & .435 & -.087 & .086 & -.290 & .231 & -.580 & .143 & -.714 & .314 & -.314 & .771 & .086 \\
\hline & $\begin{array}{l}\text { Post- } \\
\text { effort }\end{array}$ & -.348 & -.116 & .486 & .174 & .464 & $\mid-.754$ & -.429 & -.029 & -.086 & .486 & .771 & $\mid-.314$ \\
\hline \multirow[t]{2}{*}{$\begin{array}{l}\text { Cort. } \\
(\mu \mathrm{g} / \mathrm{dl})\end{array}$} & $\begin{array}{l}\text { Pre- } \\
\text { effort }\end{array}$ & .426 & .412 & -.406 & -.735 & -.485 & \begin{tabular}{|l|}
-.309 \\
\end{tabular} & .116 & $-.928 *$ & .551 & -.319 & .203 & .493 \\
\hline & $\begin{array}{l}\text { Post- } \\
\text { effort }\end{array}$ & $\mid-.319$ & .116 & .314 & .232 & .377 & $\mid-.841$ & -.829 & .486 & -.657 & . 6 & .429 & $\mid-.086$ \\
\hline
\end{tabular}

2 